\title{
Successful return to work during labor market liberalization: the case of Italian injured workers
}

\author{
Monica Galizzi ${ }^{*}$ (D), Roberto Leombruni ${ }^{2,3}$ and Lia Pacelli²,3
}

\begin{abstract}
We investigate the long term employment outcomes of Italian injured workers over a time period when the country introduced policy reforms that increased labor market flexibility but reduced job security. Using an employeremployee database matched with injury data, we observe that both before and after the reforms almost one-fourth of injured workers were no longer employed 3 years after their "first" return to work. We note a slight decrease in this share after the reforms (from 24 to 22\%) while we find a decline in workers' job security as measured by their probability of re-employment in permanent contracts. We use multinomial logit estimates to study how liberalization reforms were associated with a changing role of individual, firm, and injury characteristics in shaping long-term employment outcomes of injured workers after their recovery period. Heterogeneity analyses show that low wage employees, women, immigrants, and individuals who suffered a more severe injury were penalized more. Pre-injury individual characteristics became stronger predictors of long-term employment than firms' characteristics. In particular, we find that the advantage provided by working in larger firms was significant before the liberalization reforms, but disappeared afterward, while the advantage provided by human capital became more relevant after the liberalization.
\end{abstract}

Keywords: Occupational injuries, Return to work, Maximum medical improvement, Deregulation, Multinomial logit, Matched employer-employee data, Italy

JEL Classification: J08, J28, J6

\section{Introduction}

In Italy the cost of occupational injuries in 2007 was estimated to be equal to $2.63 \%$ of the national GDP. Onethird was attributable to safety investments and actions initiated by firms to prevent injuries. The remaining 27 billion euros were attributable to medical or indemnity costs incurred by national agencies, to production and adjustment costs sustained by employers, and to productivity losses or legal expenses faced by workers and their families (INAIL 2011). Across countries, all these expenses are known to be function of injury severity, and of the length of the time to recover and to return to work (RTW). Hence the extensive research to identify

\footnotetext{
*Correspondence: monica_galizzi@uml.edu

1 Department of Economics, University of Massachusetts Lowell, Lowell, MA 01854-2881, USA

Full list of author information is available at the end of the article
}

best practices that can speed the RTW process and the implementation of policies to facilitate it and enhance injured workers' employment (Clayton et al. 2012; Barr et al. 2010).

However, the meaning of successful RTW may vary across stakeholders (Young et al. 2005b; Leyshon and Shaw 2012). While for the insurance agency it may signify the end of disability payments, for employers it may indicate the time when productivity is fully restored. For workers it is likely to mean not only reentry to work but also ability to keep the job, the pre-injury wage, and to further advance in career (Young et al. 2005a). In this context, the seminal study by Butler et al. (1995) highlighted that the research focus on workers' first RTW can produce a very misleading picture. It does not capture the real post-injury employment dynamics, as many injured workers fail to return to stable employment after their day of maximum medical improvement, and instead drop 
off the labor force, or experience unemployment or new disability spells.

Given such emerged research focus on injuries' longer term employment outcomes, it is surprising that the literature has neglected the role played by existing labor market regulations. A handful of studies has examined whether differences in national disabilities policies (benefit generosity and eligibility requirements) contributes to different degrees of sustainable RTW (Anema et al. 2009; Barr et al. 2010; Collie et al. 2016; Burkhauser et al. 2016). However, to the best of our knowledge, to date no economic analysis has explored whether longer term employment patterns can also be associated with changes in national labor market regulations such as the ones introduced in several European countries since the 1990s to increase labor market flexibility. Our objective is to cast some light on such neglected topic. Liberalization reforms were introduced through interventions "at the margin" that facilitated and induced the creation of new more flexible contracts. However, the reforms had wider effects that changed the entire labor market functioning. They had a detrimental effect on workers' bargaining power (Ciminelli et al. 2018) and played a role in exacerbating inequalities in the labor market (Barbieri and Cutuli 2016). They triggered demand side responses in terms of job openings and personnel recruitment which changed the context and the perspectives also of incumbent, permanent workers. Given such background, we want to investigate how such changed institutional environment framed the long term employment experience of injured workers. We research this in an institutional setting that differs greatly from the North American labor market that has been the object of most existing economic studies about injured workers' RTW. In fact, in Italy injured workers are guaranteed "de facto" full wage compensation while off work, and this scenario changes the incentives to potentially speed the return to employment (Galizzi et al. 2016).

We exploit a large administrative database on work and injury histories in Italy to describe how long term employment outcomes (up to 36 months after the end of the recovery period) of injured workers evolved over 10 years when important labor market liberalization reforms were implemented (in 1998-2001). Such reforms aimed at introducing greater flexibility for employers and more employment opportunities for workers, but they were implemented in a heterogeneous way, affecting particularly those individuals who were already less protected before the reforms and bringing about or worsening a situation of great job insecurity for many sections of the Italian workforce (Berton et al. 2012; Barbieri and Scherer 2009). We examine whether such heterogeneous consequences were observable also among injured workers' long term employment patterns, in particular in terms of differences in ability to maintain their pre-injury employment and contractual status. We investigate whether different outcomes characterized injured workers whose pre injury employment characteristics (human capital accumulation, firm's size) were more likely to offer "protection" from the effects of the liberalization reforms. We also explore whether employment outcomes differed for the traditionally most vulnerable groups of workers (temporary workers, women and immigrants).

To be more specific, we estimate the probability of different employment outcomes conditional on a rich set of controls, and compute the predicted probabilities of each outcome in years before, during and after the reform period. Since the policy change did not target a particular segment of the labor market, all workers saw their long term employment outcomes potentially affected by the reforms. Hence, we cannot identify a control group to assess the causal impact of the reforms on the levels of the estimated probabilities for workers in specific contractual groups. ${ }^{1}$ Then, our identification strategy relies on comparing the differences in the employment probabilities driven by several individual, firm, and injury characteristics, and studying whether the reforms were associated with a change in these differences across all workers. What we observe is that there were many probabilities trends that were in action before the reforms. Such trends were similar but separated (parallel) across the observed characteristics. However, we find meaningful departures from such parallel trends after the reforms. In particular, we find that the advantage provided by higher employment protection (EPL)-measured by firms' size-in securing a successful outcome was significant before the liberalization reforms but is nonexistent afterward; while the advantage provided by human capital accumulation (HC)- measured by wages-increases in magnitude after the liberalization reforms.

Our study is organized as follow: in Sect. 2 we discuss the related literature, our research hypotheses about the "protective role" of some firms and individual attributes, and their testable implications; in Sect. 3 we describe the Italian relevant institutional setting and its evolution over time with specific attention to labor market deregulation. Section 4 addresses data, sample selection and methodological issues. Section 5 presents our estimated results, robustness checks and comparisons with not-injured

\footnotetext{
${ }^{1}$ At the same time, policy changes took place over several years and were concurrent with an economic slowdown (1999-2000), and with reforms in both the workers' compensation and unemployment insurance systems (see section below). This precludes us from using also a before-after strategy (exploiting, for example, interrupted time series) to assess a clear-cut causal effect of the reforms on the probabilities of different employment outcomes.
} 
workers. Finally, Sect. 6 includes a discussion of our results and our conclusions.

\section{Related literature and theoretical background}

Our aim is to describe how the long term RTW patterns of injured workers evolved over years characterized by labor market liberalization. Therefore, we build on two quite separate strands of economics literature, i.e. the one that has analyzed the conditions favoring a successful RTW and the one that has focused on the effects of labor market deregulation on the overall functioning of the labor market.

\subsection{About RTW}

The RTW literature has shown that what seems a relatively simple chain of events (some workers get injured on the job, take time off work to heal, and return to work) disguises several complexities. Workers, firms, insurance agencies, government agencies, they all may face aligning or conflicting incentives in facilitating this process (Boden and Galizzi 2017). Workers' demographics, firms' attributes, injury characteristics and workers' compensation rules about eligibility, generosity, and length of disability payment will also affect it (Anema et al. 2009; Barr et al. 2010; Collie et al. 2016). Regulations and norms about disabilities accommodation may play also a large role (Anema et al. 2009; Clayton et al. 2012; Gailey and Seabury 2010). Hence, the rich literature that over the last 30 years has studied the different factors that may facilitate workers' return to productive employment (Krause et al. 2001; Cullen 2018). However, workers' RTW may not represent the end of the chain of events ignited by the incident. A first RTW may be followed by additional spells of employment or changes in employers, or by new occupational injuries, or lead to labor force separation (Butler et al. 1995; Krause et al. 2001; Bültmann et al. 2007; Côté et al. 2008; Vogel et al. 2011; Berecki-Gisolf et al. 2012; Galizzi 2013; Biering et al. 2013; Young 2014). All these additional developments are then one more time affected by the severity and degree of full recovery from the injury (Côté et al. 2008); by workers' pre injury characteristics (Galizzi 2013); by firms' ability to provide accommodation(Høgelund and Holm 2014), and potential retaliation against the injured worker (Strunin and Boden 2004). Given the focus of our research about the potential role played by EPL and $\mathrm{HC}$, it is also important to note that these additional longer term employment outcomes can be affected by workers' attachment to the job, earnings, and job status (Awang et al. 2016; Galizzi et al. 2016; Seing et al. 2015). For example, GarcíaSerrano et al. (2010) show that highly flexible workers return to work earlier than others, ceteris paribus, possibly jeopardizing their health and future employability.
Overall cyclical economic conditions and tightness of the labor market also play a role (Institute for Work \& Health 2009). Therefore, it is quite plausible that after a first RTW, a worker's rights and opportunities to remain employed and to have access to good jobs will be associated with the more general labor laws and regulations that characterize each country, and, within each country, different sectors or firms.

\subsection{About deregulation}

Recent studies have shown that labor market deregulations introduced in several countries since the early 1990s to increase productivity and employment has reduced the share of labor income at the macroeconomic level (Ciminelli et al. 2018) and increased inequalities (Barbieri and Cutuli 2016). The literature also highlights that, when reducing employment protection legislation (EPL), workers' mobility increases while the effect on unemployment is ambiguous (Bertola 1990). Giannelli et al. (2012) estimate that in Italy the duration of the first job spell of individuals entering the labor market decreased after the deregulation reforms (they study the period 1990-2000) and this effect was not counterbalanced by a higher probability of moving quickly to a new employer. Furthermore, they observe that "the share of workers with only one job spell within 3 years decreases, while the share of those with three or more spells increases". The port of entry effect-where temporary jobs lead to permanent employment-continued after the reforms but became less noticeable, as less than half of workers could move to a permanent contract after a series of temporary spells (Berton et al. 2011). Temporary jobs may end just substituting permanent ones (Kahn 2010). In the context of occupational injuries, temporary jobs and precarious employment have been found to be associated to higher occurrence of injuries (Amuedo-Dorantes 2002; Bender et al. 2012; Giraudo et al. 2016; Koranyi et al. 2018) and more severe injuries (Picchio and Van Ours 2017) in several countries, including Italy. Because the liberalization reforms increased the prevalence of job insecurity, it is reasonable to expect an overall association with changes in employment outcomes of occupational injuries. However, to the best of our knowledge, there are no studies that describe variations of injured workers' subsequent employment and patterns of successful "first" RTW in the context of new labor market regulation.

\subsection{Our hypotheses}

Our study contributes to such body of literature to test six different hypotheses among Italian injured workers. First, even in an institutional setting where injured workers enjoy more protection compared to the one examined in North American studies, a "first" RTW is 
not a stable outcome and workers' and firms' characteristics affect such outcome:

Hp0: Occupational injuries have a substantial limiting effect on long term employment also for workers who "first" $R T W$

Hp1: The physical effect of injuries is a very important determinant of long term employment outcomes but workers' and firms' characteristics that are potentially associated with a higher likelihood of workplace accommodations play also a very large role

Furthermore, as described in detail in the section below, labor market reforms introduced in Italy in the late 1990s affected firms differently depending on specific firms' attributes such as size and unionization. Therefore,

Hp2: The probability of keeping the pre-injury job after a first RTW was reduced for workers who were employed in firms where EPL decreased due to labor law reforms

Second, we know that a worker' high wage is likely to indicate her level of human capital, as well as productivity, effort, dedication to the job, and overall value to the firm's production process. Therefore, higher wages might also imply a higher probability or staying in the same firm in the medium-long run after RTW, despite deregulation of the labor market that would allow the firm to dispose of the worker more easily. Therefore, we test the following hypothesis:

Hp3: Compared to low wage workers, high wage workers were more likely to secure their pre-injury employment relationship in the medium-long run even if EPL was reduced

On the other hand, workers who had suffered more serious injuries may be less employable, e.g. because of functional limitations due to the accident. It is an open empirical question whether deregulation of the labor market was associated with improvement or worsening of their condition. Hence we test:

Hp4: The reduction in EPL was correlated with worst long-term employment outcomes for those employees who had suffered more serious injuries

Finally, we know that women and immigrants are workers who compose the weaker segments of the labor market, e.g. they earn lower wages and are more often hired with more precarious contracts (Venturini and Villosio 2008; Olivetti and Petrongolo 2008). Hence, we test a fourth hypothesis:

Hp5: The reduction in EPL was correlated with worst long-term employment outcomes for the more vulnerable employees such as injured women and immigrants

To test these hypotheses we study a variety of long term employment outcomes: job-security (still holding the before-injury job), employment security (no more holding the before-injury job but still employed), a more precarious job (movements in and out of temporary/permanent contracts), unemployment, or new job related injuries. We study a 12 years period (1994-2005) during which Italy introduced a set of labor market liberalization reforms that we illustrate below.

\section{Institutional setting}

Italian injured workers hired with a permanent contract enjoy full job protection until the end of their recovery period. However, after their first RTW they are at risk of layoffs if no viable accommodation is found, or may quit if they cannot cope with job demands. For temporary workers the outcome is more uncertain if their contract expires before their day of maximum medical improvement. We aim at understanding whether changes in labor market regulations may be associated with modifications of long run employment outcomes across all these workers. In this paper, we focus on EPL reforms, defining a period "before" (1994-1997), a period "during" (19982001) and a period "after" (2002-2005) such reforms. In the following section, we describe these reforms and the institutional settings, as well as some additional changes introduced in those years that affected both Workers' Compensation rules and welfare provisions for the unemployed.

\subsection{Employment protection legislation and liberalization reforms}

In the initial period that we study (1994-1997), the typical labor market contract for an Italian worker was a "permanent" one, i.e. a contract with no stated termination date and implying significant firing costs for the employer in case of not-consensual termination. Such firing costs included severance payments and compensation in case of unfair dismissal. They increased with firm size in correspondence of two legal thresholds, one at 15 and another one at 60 employees (Cavaletto and Pacelli 2014). In addition, unionization typically increases with firm size, making layoffs more conflictual, lengthier and costlier for larger employers. Until the late 1990s, the 
only departures from the typical permanent contracts were apprenticeships and on-the-job-training contracts for youth. Temporary contracts were very limited and subject to strict constraints: each firm faced limits in the number of temporary employees it could hire and was required to prove the temporary nature of the occupation.

Labor market liberalization reforms were concentrated between 1998 and 2001. Reforms started in 1998 (Law Decree No. 196/1997) and introduced and regulated new types of work (such as temporary agency work and quasidependent work ${ }^{2}$ ). They continued in 2000 (Law Decree No. 61/2000) deregulating part-time contracts. Finally, in 2001 we saw the full liberalization of temporary contracts (Law Decree No. 368/2001). Now they could last a few days or up to 36 months, became renewable and faced no restrictions on their use. Afterward, only law Decree No. 276/2003 modified the EPL setting but did not introduce substantial novelties. Further and deeper reforms took place after 2008 but they are excluded from our analysis since their effects were largely affected by the macroeconomic recession. We should mention that the public sector did not undergo most of the reforms we discussed here. Instead, it faced a prolonged hiring freeze. Because of this difference, we exclude public employees from the current study.

All these were reforms "at the margin", decreasing EPL for new entrants on the labor market and for job movers, but not for incumbent workers who kept their open ended job. However, while small firms faced very low EPL even before the reforms were introduced, larger firms took advantage of them to decrease the average EPL of their workforce by expanding new hires with flexible contracts, and by enjoying stronger bargaining power (Ciminelli et al. 2018).

The effect of the reforms became rapidly visible, as non-permanent contract workers in the private sector increased from 600,000 in the first quarter of 1998 to about 1.2 million in the first quarter of 2006 (Eurostat 2018).

\subsection{Workers' compensation}

In Italy, a public insurance system provides medical and disability benefits to all employees, both permanent and temporary workers, to all self-employed manual workers and to a part of non-manual self-employed workers. Those excluded from the public system-mostly selfemployed workers in the trade sector-have to resort to the private insurance sector (but they do not have the obligation to do so). ${ }^{3}$ The public system is managed by

\footnotetext{
${ }^{2}$ Formally "self-employment" this is a de facto subordinate employment relationship. It is similar to a free-lance job and might be called also contractwork.

${ }^{3}$ All self-employed workers are excluded from our analysis.
}

the National Workers' Compensation Agency (INAIL), and is financed by firms through premiums that are proportional to payroll, increase with jobs risk, and are adjusted through experience rating. Workers who get injured are entitled to a recovery period, the length of which is established by a doctor who is certified to work for INAIL. They receive paid medical care directly or indirectly provided by INAIL, and disability benefits ranging from 60 to $75 \%$ of their earnings. However, a topup granted by employers according to collective agreements allows injured employees to earn a de-facto full wage replacement during their absence from work (Galizzi et al. 2016). The worker compensation system was the object of only minor adjustments in the last decades. The only relevant reform was delivered in 2000 (DLgs $38 / 2000$ ). It introduced coverage also for incidents occurring on the way to or from work, ${ }^{4}$ a compensation for the so called "biological damage" (Rossi 2002), and modified injury severity thresholds that entitle injured workers to permanent disability (PPD) benefits. PPD is measured on a $0-100 \%$ scale and is set by the law in a very detailed way. Before the 2000 reform, workers with a PPD up to $10 \%$ (e.g. a fracture of the atlas without persistent neurological symptoms) did not receive any compensation after the completion of the healing period, while over the $10 \%$ threshold an annuity was paid compensating for long term income losses. The 2000 reform increased the generosity of the workers' compensation PPD benefits: the threshold without compensation was lowered to $5 \%$ (e.g. a detectable scar, not visible on the face or neck); from 6 to $15 \%$ a lump sum compensating not the income losses but the biological damage is now paid according to the severity, the gender and the age of the worker ${ }^{5}$; above the $15 \%$ threshold the compensation is paid with an annuity, and pays for both the biological- and income loss. ${ }^{6}$

\subsection{Unemployment benefits}

Up to 2005 the system assisting workers who lost their job was highly segmented. Workers laid off by larger (above 15 employees) manufacturing firms through collective bargaining (involving 5 or more employees) could enjoy generous "mobility benefits": compensation up to $75 \%$ of their wage for up to 4 years according to age and area of work. All other unemployed individuals were

\footnotetext{
${ }^{4}$ Such incidents in itinere are excluded from our analysis, as they were unobservable up to 2000

5 For example, a fracture of the atlas with 10\% PPD would grant a lump sum of 21,700 euro-about 1 year of average salary-for a man under 20 years of age.

${ }^{6}$ Such annuity increases with the degree of PPD: from less than 2 months of average salary to more than 1 year of average salary for a PPD equal to $100 \%$.
} 
compensated by a system of unemployment benefits that was poorly endowed, provided only a $30 \%$ replacement rate for 6 months (40\% for up to 9 months starting from 2001) and was subject to strict eligibility conditions on past employment ${ }^{7}$; overall, it was characterized by very low take-up rates and did not reach the minimum standards set by the 1952 ILO Social Security Convention until 2008 (Leombruni et al. 2012).

\section{Study population and methods}

\subsection{Data}

We use a database that combines individual employment histories from the Work Histories Italian Panel (WHIP) with injuries records from INAIL, the Italian National Workers' Compensation Agency. The matched database is a 1:15 random sample of the population (about 1.5 million workers each year) covering the period 1994-2012, generating a unique source of information for the analysis of occupational injuries.

WHIP's reference population includes all Italian workers and pensioners. It excludes only public sector employees hired with an open-ended contract and high skilled professions (e.g., lawyers) who are compensated with different insurance funds. The dependent employment section of WHIP is a matched employer-employee database that includes start and end dates of each employment spell, as well as worker characteristics (age, sex, place of birth), job characteristics (temporary vs. permanent contract, full-time vs. part-time, occupation, location), labor market outcomes (the number of days and weeks worked, earnings and social security payments) and firm characteristics (size, opening and closing date, sector, location, monthly new hires and separations, average wages).

INAIL data include a description of all injuries causing permanent or temporary disabilities across the whole country and with time off work longer than 3 days. The data records a description of the injury event itself (when, how, where) and its consequences (nature of injury, part of body, length of temporary disability payment, and degree of permanent disability-if any).

The INAIL dataset and the WHIP dependent employment section have been matched and this is the dataset on which we base our analysis (see Bena et al. 2012, and Galizzi et al. 2016, for further details). ${ }^{8}$

\footnotetext{
${ }^{7}$ Such conditions were: sector of activity (mostly manufacturing firms), at least 2 years of past employment, and at least 1 year of paid contributions over the last 2 years. As a result, the take up rate was very low.

${ }^{8}$ Our study did not require ethics review and approval. In fact, the data we use has been listed under the Italian National Statistical Program that includes data-collection projects that comply with the national regulation on all issues regarding the use of personal data. The data has been positively evaluated by the Italian authority that is responsible to guarantee and protect privacy.
}

\subsection{Sample selection}

For the purpose of this work, we select only employees who had a work incident between 1994 and 2005. As we observe outcomes up to 3 years after their recovery period this brings us at the beginning of the economic crisis in 2008. After that year, the Italian macroeconomic environment was deeply affected by the consequences of the financial crisis, and became less comparable to the previous decade.

We drop fatal events and injuries occurring on the way to or from work (as they were not compensated and therefore recorded before 2000), as well as those occurring in agriculture (where many are self-employed), and in education, health and personal services (which are mainly public sectors for which we do not have corresponding WHIP data).

As in most studies concerning injured workers, a serious concern is the issue of underreporting of injuries (Boden and Ozonoff 2008; Picchio and Van Ours 2017), mainly from small establishments (Wuellner et al. 2016; Oleinick et al. 1995). Indeed, smaller firms have higher ability to under-report less severe injuries because governments' health and safety controls are less frequently implemented among small firms. Furthermore, the additional insurance costs generated by an incident can be more significant for a small business and induce a larger incentive to underreport (evidence on Italy is provided in Galizzi et al. 2016). For our study, such concern is particularly relevant because it entails a potential bias in our estimations. As we described above, firm size modifies the degree of EPL, so that the estimated effect of the latter can be blurred by underreporting. Therefore, we exploit the information on the nature of incidents to study only injuries which usually require immediate treatments at a hospital (fractures, anatomic losses and removals of an alien corpus). By implementing this restriction we limit the likelihood of an underreporting bias because hospitals are required to report injuries to INAIL.

Our final sample includes about 29,000 incidents for 27,442 workers. The sample composition does not change in a relevant way over the years we study with respect to

\footnotetext{
Footnote 8 (continued)

Please notice that in case of acceptance for publication, we will not be able to directly provide the dataset we used because the data owner is the Italian Ministry of Health, and we had access to it according to a strict confidentiality agreement. The data can be accessed by any researcher establishing a specific research agreement with the Italian Ministry of Health, however. We are obviously ready to provide information to guide other researchers through the procedures for accessing the data on injuries. Please also notice that all the results and descriptive statistics only related to the labor market-e.g. work contracts or wages - can be easily replicated with publicly accessible datasets also based on INPS archives (e.g. LOSAI, distributed by the Italian Ministry of Welfare). The copies of the computer programs used to generate the results presented in the paper are available from the authors.
} 
Table 1 Unconditional probabilities of post injury long term employment outcomes

\begin{tabular}{|c|c|c|c|c|}
\hline \multirow[t]{2}{*}{ 1994-1997 } & \multicolumn{4}{|c|}{ Outcome after $\mathrm{n}$ months since RTW } \\
\hline & 3 months & 6 months & 12 months & 36 months \\
\hline Non work & 15.0 & 14.7 & 16.9 & 25.4 \\
\hline Employed in the same firm & 79.9 & 76.9 & 69.2 & 48.5 \\
\hline Employed in a different firm-permanent contract & 3.7 & 6.2 & 10.6 & 19.5 \\
\hline Employed in a different firm-temporary contract & 1.0 & 1.6 & 2.6 & 5.9 \\
\hline On leave due to a new_injury & 0.4 & 0.6 & 0.8 & 0.7 \\
\hline Total & 100.0 & 100.0 & 100.0 & 100.0 \\
\hline 1998-2001 & 3 months & 6 months & 12 months & 36 months \\
\hline Non work & 14.9 & 13.8 & 15.1 & 24.1 \\
\hline Employed in the same firm & 78.1 & 75.1 & 67.2 & 46.8 \\
\hline Employed in a different firm-permanent contract & 4.3 & 7.2 & 11.3 & 19.9 \\
\hline employed in a Different firm-temporary contract & 2.2 & 3.4 & 5.7 & 8.5 \\
\hline On leave due to a new_injury & 0.5 & 0.6 & 0.8 & 0.8 \\
\hline Total & 100.0 & 100.0 & 100.0 & 100.0 \\
\hline 2002-2005 & 3 months & 6 months & 12 months & 36 months \\
\hline Non work & 15.4 & 14.1 & 15.2 & 23.0 \\
\hline Employed in the same firm & 77.9 & 74.9 & 67.7 & 48.6 \\
\hline Employed in a different firm-permanent contract & 3.6 & 5.7 & 9.5 & 17.0 \\
\hline Employed in a different firm-temporary contract & 2.8 & 4.6 & 6.9 & 11.2 \\
\hline On leave due to a new_injury & 0.3 & 0.8 & 0.7 & 0.2 \\
\hline Total & 100.0 & 100.0 & 100.0 & 100.0 \\
\hline
\end{tabular}

Among those who were hired pre-injury with a permanent contract, only $1.7,1.4$ and $0.8 \%$ (in the three periods respectively) became temporary contract workers in the same firm - out of all possible outcomes. Among those who were hired pre-injury with a temporary contract in the same three periods, $18.2 \%, 15.2 \%$ and $12.6 \%$ became permanent contract workers in the same firm—out of all possible outcomes

the part of body affected and to the nature of injury, but for a 4 p.p. increase in the prevalence of fractures, from $48.9 \%$ before the reforms to $53 \%$ after them (see Table 2).

\subsection{Measures of RTW outcomes}

The outcome we analyze is the work status of the person $n$ months (up to 36 months) after what we call their "first" RTW. ${ }^{9}$ We face no right censoring, as the database covers the period up to 2012 .

The outcomes we consider are: non-work, employed in the pre-injury firm, employed in a different firm with a permanent contract, employed in a different firm with a

\footnotetext{
${ }^{9}$ This is what is known as the day of "Maximum Medical Improvement" and is often used as a RTW measure in the literature. As we mentioned before,in the case of all Italian permanent contract this day coincides with the day of RTW because employees return to their previous job by law. However, Italian temporary contract workers can be unemployed upon return if their contract expires before the end of their healing period. In this latter case our data measure the employment outcome $n$ months after the recovery period. We cannot identify these cases. This is unfortunate because injured workers in temporary contracts were a small portion of our injured population, but a portion that doubled (form 8 to $16 \%$ ) over the 10 years we study.
}

temporary contract, ${ }^{10}$ on leave because of a new injury. Unconditional probabilities (Table 1) show that the most likely outcome was maintaining the pre-injury job. However, such probability was far below $100 \%$ across all three periods and decreases as time since recovery passes. Non-work was the second most likely outcome (Hp0). Regardless of time period, it affected almost one-fourth of injured workers and increased over time.

\subsection{Statistical analysis}

To test Hp1 we estimate a standard multinomial logit model of the probability of different employment outcomes at different intervals (12 and 36 months) after the "first" RTW, where $y_{i}$ takes values $\mathrm{j}=0$ for non-work, $j=1$ if employed in the pre-injury firm, $j=2$ if employed in a different firm with a permanent contract, $j=3$ if employed in a different firm with a temporary contract, $j=4$ if on leave because of a new incident (hence $K=5$ ):

$$
\operatorname{Prob}\left(y_{i}=j\right)=\frac{e^{b_{j} X_{i}}}{1+\sum_{k=0}^{K-1} e^{b_{k} X_{i}}}
$$

\footnotetext{
${ }^{10}$ Fixed term, free-lance, training or apprentice contracts.
} 
Table 2 Summary statistics

\begin{tabular}{|c|c|c|c|c|}
\hline Period & Statistic & 1994-1997 & 1998-2001 & 2002-2005 \\
\hline Lagged real daily wage & Mean & 62.89 & 62.3 & 61.55 \\
\hline $\begin{array}{l}\text { Wage above the mean wage by occupation in the } \\
\text { firm }\end{array}$ & Share & 0.27 & 0.25 & 0.25 \\
\hline Past intermittent spells & Mean & 0.42 & 0.51 & 0.5 \\
\hline Number of employees in the firm & Median & 25.08 & 23.33 & 22.33 \\
\hline Growing firms & Share & 0.39 & 0.44 & 0.43 \\
\hline Shrinking firms & Share & 0.25 & 0.24 & 0.23 \\
\hline Firm age & Mean & 15.86 & 16.18 & 16.58 \\
\hline Excess turnover & Mean & 0.31 & 0.33 & 0.32 \\
\hline Past illness rate & Mean & 0.18 & 0.18 & 0.19 \\
\hline Years of experience plus firm tenure & Mean & 7.17 & 8.19 & 9.1 \\
\hline Female & Share & 0.08 & 0.09 & 0.09 \\
\hline Temporary contract & Share & 0.08 & 0.14 & 0.16 \\
\hline Part time & Share & 0.02 & 0.03 & 0.05 \\
\hline Migrants & Share & 0.1 & 0.17 & 0.26 \\
\hline Manual occupation & Share & 0.94 & 0.93 & 0.93 \\
\hline Worker's age & Mean & 36.7 & 36.93 & 37.96 \\
\hline Unemployment rate & Mean & 7.65 & 6.5 & 5.44 \\
\hline North-west & Share & 0.31 & 0.33 & 0.33 \\
\hline North east & Share & 0.28 & 0.29 & 0.28 \\
\hline Center & Share & 0.17 & 0.18 & 0.17 \\
\hline South & Share & 0.24 & 0.21 & 0.22 \\
\hline Manufacturing & Share & 57.36 & 53.77 & 48.5 \\
\hline Construction & Share & 21.8 & 20.09 & 24.14 \\
\hline Services & Share & 20.85 & 26.14 & 27.36 \\
\hline Fracture & Share & 48.9 & 52.95 & 52.99 \\
\hline Anatomic loss & Share & 8.58 & 7.87 & 8.65 \\
\hline Alien corpus & Share & 42.53 & 39.18 & 38.36 \\
\hline Trunk & Share & 0.3 & 0.3 & 0.3 \\
\hline Head & Share & 25.1 & 32.5 & 33.1 \\
\hline Back & Share & 8.1 & 9.5 & 7.7 \\
\hline Lower extremities & Share & 19.2 & 19.9 & 21.2 \\
\hline Upper extremities & Share & 37.3 & 37.8 & 37.9 \\
\hline Days off work after the injury & Mean & 57.00 & 62.21 & 65.76 \\
\hline
\end{tabular}

As explained in the text, we study only injuries which require immediate treatments at a hospital (fractures, anatomic losses and removals of an alien corpus)

We then examine how probabilities changed during and after the labor market reforms for workers characterized by different pre-injury EPL and HC, i.e. we interact the covariates of interest with the three reform periods. We define a set of dummies $\mathbf{D}=\left\{\mathrm{D}_{1}, \mathrm{D}_{2}, \mathrm{D}_{3}\right\}$ signaling respectively periods "before" (1994-1997), "during" (19982001) and "after" (2002-2005) market liberalization reforms. Not all covariates $\mathrm{X}$ are actually interacted with $\mathbf{D}$ (although most of them are, as explained in the empirical section); hence the estimated regressors in Eq. (1) can be further decomposed as $b_{j} X_{i}=g_{j} Z_{i} * D+h_{j} W_{i}$.

Given our research hypotheses the covariates of main interest are the following. (i) A measure of EPL ( $\log$ of the number of employees in the firm $^{11}$ ) as firm size is highly related to firing costs and union protection to test $\mathbf{H p 2}$.

(ii) A measure of human capital (log of 1-year-lagged real daily wage) capturing individual productivity, status and labor market value to test $\mathrm{Hp3}$.

(iii) A measure of injury severity (log of days off work) to investigate whether more seriously injured employees experienced different employment outcomes before and after the reforms to test $\mathrm{Hp} 4$.

\footnotetext{
$\overline{{ }^{11} \text { Head-count of individuals on the firm payroll, averaged over the calendar }}$ year.
} 
We add several controls to capture pre-injury individual health (workers' past illness rate and age), propensity to change jobs (past intermittent employment spells, ${ }^{12}$ and total work experience ${ }^{13}$ ), as well as firm's propensity to establish long-term employment relationships (excess turnover ${ }^{14}$ ). All these controls are interacted with the period (pre, during, after the reforms) as they might be correlated with the institutional environment, so that conditional on period they can provide the relative importance of each of these factors. The role of these controls is to separate the variables of main interest (firm size, wage) from the effect of observable heterogeneity in workers' health and attitudes and firms' policies.

We also include further regressors that we do not interact with periods but believe could be important determinant of successful RTW such as demographic characteristics. We include a measure of the relative "importance" of the individual worker to the firm: whether her pre-injury wages was above the mean wage of other workers employed at the same time, in the same occupation and in the same firm; whether they were employed part time, or performing manual tasks. We include information about outcomes that are clearly related to injury severity and affect subsequent employment: the nature of the injury (in our case limited to fractures, anatomic losses and removals of an alien corpus), and whether the injury had resulted in a severe permanent partial disability (PPD), (PPD rating $>17 \%$ ). Finally, we account for the business cycle: industrial sectors, geographical areas, and regional unemployment rate by gender, as well as firm's experienced growth or decline in employment. Last, we add firm's age as a proxy for its stability over time.

Summary statistics of all our covariates, calculated by time periods $\mathrm{D}$, are presented in Table 2 . Notice that males and manual workers are the vast majority of our sample, as we are focusing on individuals employed in occupations highly exposed to the risk of incidents. The most notable changes across the time periods are the increase in the number of immigrants (an increase of 16 percent point over 10 years) and the decline in unemployment rate, as the business cycle slowly improves from the recession of early 1990s to the recovery or early 2000 . Also, time off work after the injury lengthens. Finally, the percent of temporary workers in our sample of injured

\footnotetext{
${ }^{12}$ We count one change for workers who went from employment to unemployment, two changes if they went from employment to unemployment to employment again and so on. We then divide the total number of changes by the total number of pre-injury quarters.

13 Past experience plus firm tenure, in days - at the day of the accident.

${ }^{14}$ Gross worker turnover minus (absolute value of) job creation at the firm level. This measures a firm's propensity to keep or rotate its workforce.
}

workers increases from $8 \%$ in the first period, to $14 \%$ in the second and $16 \%$ in the third. Over the same period temporary workers as percentage of the total number of Italian employees were $7.5 \%, 9.5 \%$ and $10.9 \%$ (Eurostat 2018).

Finally, we stratify our analysis by type of employment contract, i.e. we estimate our models including and excluding temporary contract workers, to assess whether the liberalization reforms affected them differently. We do so to describe the patterns of "first" RTW outcomes both across all employees (regardless of pre injury contractual status) and only for permanent contract workers. The goal is to cast some light on the hypothesis that the overall RTW patterns we detect were driven mainly by the more flexible part of the work force. For the same reason we also stratify by gender and by nationality, to cast more light on the outcomes for most vulnerable workers (Hp. 5). ${ }^{15}$ We present our main results from the multinomial logit model plotting the conditional probabilities of the different outcomes in different periods:

$$
\operatorname{Prob}\left(y=j \mid D=D_{n}, Z_{m}=a, X_{-}\right)
$$

where $n$ indicates one of the three periods, $\mathrm{X}_{-}$indicates the set of all $\mathrm{X}$ excluding $\mathrm{Z}_{\mathrm{m}}$, and $\mathrm{Z}_{\mathrm{m}}$ can refer to individual wage, firm size or length of absence due to the incident, and $a$ indicates a specific value (usually a quartile) of $Z_{m}$. When we estimate Eq. (2) we set the values of variables $\mathrm{X}_{-}$at their sample average.

Then, Hp2 can be written as

$$
\begin{aligned}
& \operatorname{Prob}\left(y=1 \mid D=D_{1}, \text { firmsize }=\text { large }, X_{-}\right) \\
& \quad>\operatorname{Prob}\left(y=1 \mid D=D_{3}, \text { firmsize }=\text { large, } X_{-}\right)
\end{aligned}
$$

i.e. in a firm facing EPL reduction due to the reform (large firm), the probability of keeping the pre-injury job (outcome 1) in the pre-reform period (period 1) is larger than in the post-reform period (period 3).

$\mathrm{Hp} 3$ can be written as

$$
\begin{aligned}
& \operatorname{Prob}\left(y=1 \mid D=D_{1}, \text { wage }=\text { low }, X_{-}\right) \\
& \quad>\operatorname{Prob}\left(y=1 \mid D=D_{3}, \text { wage }=\text { low }, X_{-}\right)
\end{aligned}
$$

i.e. for a worker earning a low wage, the probability of keeping the pre-injury job (outcome 1) in the pre-reform period (period 1) is larger than in the post-reform period (period 3).

Analog inequalities can be written for the other hypotheses.

\footnotetext{
${ }^{15}$ When not stratified, we add to the model controls for gender and nationality as well.
} 
Table 3 Conditional probabilities of outcomes 1 and 3 years after "first" RTW

\begin{tabular}{|c|c|c|c|c|c|c|c|c|c|}
\hline & \multicolumn{4}{|l|}{1 year } & & \multicolumn{4}{|l|}{3 years } \\
\hline & Margin & Std. Err. & [90\% Conf. & Interval] & & Margin & Std. Err. & [90\% Conf. & Interval] \\
\hline No work & & & & & No work & & & & \\
\hline 1994-1997 & 0.153 & 0.004 & 0.147 & 0.160 & 1994-1997 & 0.240 & 0.005 & 0.232 & 0.247 \\
\hline 1998-2001 & 0.137 & 0.004 & 0.131 & 0.143 & 1998-2001 & 0.230 & 0.004 & 0.222 & 0.237 \\
\hline 2002-2005 & 0.141 & 0.004 & 0.135 & 0.148 & $2002-2005$ & 0.220 & 0.005 & 0.212 & 0.227 \\
\hline Same firm & & & & & Same firm & & & & \\
\hline 1994-1997 & 0.710 & 0.005 & 0.702 & 0.718 & 1994-1997 & 0.503 & 0.005 & 0.494 & 0.512 \\
\hline 1998-2001 & 0.699 & 0.005 & 0.691 & 0.706 & 1998-2001 & 0.493 & 0.005 & 0.485 & 0.501 \\
\hline 2002-2005 & 0.700 & 0.005 & 0.692 & 0.708 & $2002-2005$ & 0.502 & 0.005 & 0.494 & 0.511 \\
\hline Other perm & & & & & Other perm & & & & \\
\hline 1994-1997 & 0.106 & 0.004 & 0.100 & 0.112 & 1994-1997 & 0.195 & 0.004 & 0.188 & 0.202 \\
\hline 1998-2001 & 0.107 & 0.003 & 0.102 & 0.112 & 1998-2001 & 0.194 & 0.004 & 0.187 & 0.200 \\
\hline 2002-2005 & 0.089 & 0.003 & 0.084 & 0.094 & $2002-2005$ & 0.168 & 0.004 & 0.162 & 0.175 \\
\hline Other temp & & & & & Other temp & & & & \\
\hline 1994-1997 & 0.024 & 0.002 & 0.021 & 0.026 & 1994-1997 & 0.055 & 0.002 & 0.051 & 0.059 \\
\hline 1998-2001 & 0.050 & 0.002 & 0.046 & 0.054 & 1998-2001 & 0.076 & 0.003 & 0.072 & 0.081 \\
\hline 2002-2005 & 0.063 & 0.003 & 0.058 & 0.067 & $2002-2005$ & 0.108 & 0.004 & 0.102 & 0.113 \\
\hline New injury & & & & & New injury & & & & \\
\hline 1994-1997 & 0.007 & 0.001 & 0.006 & 0.009 & 1994-1997 & 0.007 & 0.001 & 0.005 & 0.008 \\
\hline 1998-2001 & 0.008 & 0.001 & 0.006 & 0.009 & 1998-2001 & 0.007 & 0.001 & 0.006 & 0.009 \\
\hline 2002-2005 & 0.007 & 0.001 & 0.006 & 0.009 & $2002-2005$ & 0.002 & 0.001 & 0.001 & 0.003 \\
\hline
\end{tabular}

Reference outcome: employed at same pre injury firm. Stata 15 commands: margins. Standard errors: delta method

\section{Results}

Estimated conditional probabilities of each outcome at 1 and 3 years after the "first" RTW (Table 3) confirm the picture previously suggested by the unconditional probabilities (Table 1). The reforms were not associated with changes in the average probability of remaining with the pre-injury firm and this remained by far the most likely long term employment outcome. At the same time, the probability of non-work decreased at the start of the reform (after period 1), but new employment became less secure. In fact, the probability of getting a new job with a permanent contract decreased after the completion of the reform (after period 2), and that of getting a temporary contract in another firm increased significantly in every period and roughly doubled after 36 months. Being off work because of a new work related injury remained an extremely unlikely event that was not influenced by the reforms. Therefore, we will not further discuss the results about this very last outcome.

\subsection{Determinants of employment patterns}

Our first goal is to test whether the above discussed trends are influenced by firm, individual, and injury characteristics. Table 4 presents our results regarding employment outcomes 1 year after a "first" RTW. ${ }^{16}$ In terms of demographic characteristic, gender is not associated with a higher likelihood of leaving employment and foreigners are actually more likely to continue working. We would expect older workers to recover less quickly from injuries but, at the same time, employers to be more willing to accommodate workers who are longterm employees of the firm. Infact, we find that older workers are more likely to either stop working or to remain employed with the pre injury employer. Indeed, consistently with human capital theory, over the 10 years we study, higher past experience (general human capital) and lower past mobility (specific human capital, as measured by intermittencies in past career) help individuals in securing the pre-injury job; both effects become stronger during and after the reforms. High wage workers (during and after the reform), and workers with higher wage compared to their coworkers, are less likely to be unemployed or to move to a flexible contract. This could indicate that employers are more willing to invest in accommodations for higher productivity or higher status employees.

\footnotetext{
${ }^{16}$ Full estimation results for the 3 years period are available upon request. We also ran estimation to test the significance of periods' differences. We included separate dummies for the three reforms periods. Results did not change (see Additional file 1: Table S1).
} 
Table 4 Multinomial logit model of employment outcomes 1 year after "first" RTW (all workers)

\begin{tabular}{|c|c|c|c|c|}
\hline & Not working & $\begin{array}{l}\text { Employed at other firm, } \\
\text { permanent contract }\end{array}$ & $\begin{array}{l}\text { Employed at other firm, } \\
\text { temporary contract }\end{array}$ & $\begin{array}{l}\text { New Injury } \\
\text { related absence }\end{array}$ \\
\hline Female & -0.143 & $-0.244^{* *}$ & 0.196 & 0.259 \\
\hline Migrant & $-0.129^{* *}$ & $0.191^{* * *}$ & $0.151^{*}$ & -0.128 \\
\hline $\ln ($ age) & $1.039^{* * *}$ & $-0.339^{* * *}$ & $-1.264^{* * *}$ & $0.905^{* * *}$ \\
\hline Period $=1 \times$ lagged real daily wage & -0.081 & 0.099 & -0.292 & $-0.735^{*}$ \\
\hline Period $=2 \times$ lagged real daily wage & $-0.478^{* * *}$ & -0.141 & $-0.720^{* * *}$ & -0.489 \\
\hline Period $=3 \times$ lagged real daily wage & $-0.604^{* * *}$ & $-0.239^{*}$ & $-0.920^{* * *}$ & -0.458 \\
\hline Wage above the firm's mean wage & $-0.099^{* *}$ & -0.012 & $-0.218^{* *}$ & $-0.386^{* *}$ \\
\hline Part time & 0.17 & 0.171 & -0.114 & -1.207 \\
\hline Manual occupation & -0.025 & $0.304^{* * *}$ & $0.502^{* * *}$ & 0.743 \\
\hline Period $=1 \times \ln$ (total experience) & $-0.707^{* * *}$ & $-0.181^{* * *}$ & $-0.565^{* * *}$ & -0.095 \\
\hline Period $=2 \times \ln$ (total experience) & $-0.545^{* * *}$ & -0.077 & $-0.333^{* * *}$ & -0.264 \\
\hline Period $=3 \times \ln$ (total experience) & $-0.486^{* * *}$ & $-0.095^{*}$ & $-0.225^{* * *}$ & $-0.350^{* *}$ \\
\hline Period $=1 \times$ past intermittent emp. spells & $1.047^{*}$ & $1.786^{* * *}$ & 0.842 & $2.001^{* *}$ \\
\hline Period $=2 \times$ past intermittent emp. spells & $1.010^{*}$ & $1.363^{* *}$ & $1.195^{* *}$ & 0.759 \\
\hline Period $=3 \times$ past intermittent emp. spells & $1.715^{* * *}$ & $2.732^{* * *}$ & $2.501^{* * *}$ & 1.703 \\
\hline Period $=1 \times$ past illness rate & 0.049 & $0.370^{*}$ & -0.253 & $1.463^{* * *}$ \\
\hline Period $=2 \times$ past illness rate & $0.540^{* * *}$ & 0.249 & $0.734^{* * *}$ & $1.818^{* * *}$ \\
\hline Period $=3 \times$ past illness rate & $0.374^{* *}$ & $0.525^{* *}$ & $0.649 * * *$ & $1.554^{* * *}$ \\
\hline Period $=1 \times \ln$ (days off after 1 st injury) & $0.308^{* * *}$ & $0.106^{* * *}$ & $0.186^{* *}$ & 0.032 \\
\hline Period $=2 \times \ln$ (days off after 1st injury) & $0.284^{* * *}$ & $0.140^{* * *}$ & $0.151^{* * *}$ & 0.037 \\
\hline Period $=3 \times \ln$ (days off after 1 st injury) & $0.285^{* * *}$ & $0.102^{* * *}$ & $0.131^{* * *}$ & 0.132 \\
\hline Permanent damage $>17 \%$ & $0.475^{* * *}$ & 0.098 & -0.159 & 0.325 \\
\hline Alien corpus & $0.404^{* * *}$ & 0.051 & $0.248^{* *}$ & $0.462^{*}$ \\
\hline Fracture & 0 & 0 & 0 & 0 \\
\hline Anatomic loss & -0.116 & -0.087 & -0.11 & -0.599 \\
\hline In (firm age) & $-0.132^{* * *}$ & $-0.191^{* * *}$ & $-0.166^{* * *}$ & -0.054 \\
\hline Period $=1 \times \ln$ (firm size) & $-0.082^{* * *}$ & $-0.163^{* * *}$ & $-0.117^{* * *}$ & 0.001 \\
\hline Period $=2 \times \ln$ (firm size) & -0.028 & $-0.103^{* * *}$ & $0.059^{* *}$ & 0.082 \\
\hline Period $=3 \times \ln$ (firm size) & 0.001 & -0.03 & $0.103^{* * *}$ & $0.094^{* *}$ \\
\hline Growing firm & $0.252^{* * *}$ & $0.342^{* * *}$ & $0.418^{* * *}$ & -0.089 \\
\hline Shrinking firm & $0.689^{* * *}$ & $0.962^{* * *}$ & $0.900^{* * *}$ & 0.263 \\
\hline Period $=1 \times$ firm excess turnover & $0.478^{* * *}$ & $0.551^{* * *}$ & $0.535^{* * *}$ & -0.505 \\
\hline Period $=2 \times$ firm excess turnover & $0.716^{* * *}$ & $0.492^{* * *}$ & $0.860^{* * *}$ & -0.125 \\
\hline Period $=3 \times$ firm excess turnover & $0.678^{* * *}$ & $0.623^{* * *}$ & $0.928^{* * *}$ & 0.411 \\
\hline Manufacturing & 0 & 0 & 0 & 0 \\
\hline Constructions & $0.411^{* * *}$ & $0.410^{* * *}$ & $0.191^{* *}$ & -0.053 \\
\hline Services & 0.082 & $0.392^{* * *}$ & $0.256^{* * *}$ & 0.187 \\
\hline North west & 0 & 0 & 0 & 0 \\
\hline North east & $-0.110^{* *}$ & -0.01 & 0.002 & 0.115 \\
\hline Center & -0.07 & $-0.127^{*}$ & 0.094 & $0.386^{*}$ \\
\hline South & -0.062 & $-0.233^{* *}$ & 0.073 & 0.569 \\
\hline Unemployment rate & $0.024^{* * *}$ & -0.004 & $-0.034^{* *}$ & -0.038 \\
\hline Constant & $-0.884^{* *}$ & -0.311 & $5.402^{* * *}$ & $-5.297^{* * *}$ \\
\hline
\end{tabular}

Reference outcome: employed at same preinjury firm. Stata 15 commands: mlogit ${ }^{*} \mathrm{p}<0.10,{ }^{* *} \mathrm{p}<0.05,{ }^{* * *} \mathrm{p}<0.01$ 
Viceversa, manual workers seem to be more "disposable", less able to maintain their pre injury job. The same seems true for individuals employed in constructions and in services, with construction workers much more likely to stop working after a "first" RTW. Past illnesses increase the likelihood of being unemployed, or of being employed with a flexible contract, but only during and after the reforms. As expected, more severe injuries jeopardize a successful RTW: injuries resulting in a severe permanent disability (above the 17\% rating that entitles workers to permanent annuity payments benefits) are more likely to lead to no work, and injuries that required a longer time to recover are clearly associated with both a much higher likelihood of stop working or of separating from the preinjury employer.

As far as firms are concerned, we find that larger and older companies guarantee more employment continuity to their injured workers, while workers are less likely to maintain jobs with firms that were either growing or shrinking. Being employed in a high turnover firm decreases the likelihood of keeping the pre-injury job, with no noticeable changes across periods.

This first set of results is consistent with our Hp1. It confirms the role played by the direct physical effect of injuries but suggests also the important role played by workers' characteristics and firms' ability and willingness to accommodate their injured employees after the firstand for permanent workers guaranteed-RTW.

To better describe how these findings vary over the 10 years we study, we are performing also a comparison between the differential degree of "protection" provided by being employed in very small, small or large organizations, and how this differential degrees of protection changed in different reform periods (as for $\mathrm{Hp} 2$ ); or a comparison between the differential degree of "protection" provided by enjoying a low, average or high endowment of human capital, and how this differential degree of protection changed in different reform periods ${ }^{17}$ (as for $\mathrm{Hp} 3$ ). We also want to explore whether the estimated probabilities change by severity of the injury (as for $\mathrm{Hp} 4$ ), gender, and nationality (as for $\mathrm{Hp} 5$ ), and whether results vary by pre-injury contract type. We use our main estimation results from the multinomial logit model (Table 4) to plot the conditional probabilities of the different employment outcomes in different periods and for different values of the covariates of interest, as specified in $\mathrm{Eq}$ (2). In the following figures we look at the slopes

\footnotetext{
${ }^{17}$ Our estimations show that there were no changes in these differential degrees of protection before the reform started in 1998. See Additional file 1: Figure S1. We also conducted separate analyses by industrial sectors. Results do not change and are available upon request. We thank an anonymous referee for suggesting these controls.
}

of the marginal effects of covariates over time, as they indicate the conditional probability of outcome $j$ at values $a=\left\{a_{1}, a_{2}, a_{3}\right\}$ of the covariate of interest $\mathrm{Z}$ over time, i.e. as the reforms develop.

\subsection{Role of employment protection legislation and human capital}

Figure 1 ("Conditional probability of outcomes after one year since $R T W$, by firm size (10, 100, 1000 employees") plots how the conditional probabilities of our four main RTW outcomes changed over the three reforms periods and varied in correspondence of the size of the firm that was employing the worker when the incident occurred. We show only results for outcomes 1 year after the "first" RTW but the ones for 3 years after are substantially equivalent (see Additional file 1: Figure S4). Each line refers to a given firm size representative of small, medium and large Italian firms. ${ }^{18}$ The model is estimated on a continuous measure of firm size. Here we compute the predicted probabilities of outcomes (marginal effects) at arbitrary $^{19}$ values of firm size (10, 100 and 1000 employees) chosen to be representative of different EPL settings caused by the legal provisions for compensation in case of unfair dismissal, or the likely presence of unions: small firms (10 employees) below the lower legal threshold (set at 15 employees in a single local unit or a local area ${ }^{20}$ ); medium size firms (100 employees) above the upper legal threshold (set at 60 employees considering all local units and local areas); large and usually unionized firms (1000 employees). Lines plot these margins over time and permit us to describe how the "advantage" of being employed in a large firm changed over time.

We find that pre-injury employment at a larger firm did no longer secure a job in the same firm after the reforms started: the conditional probability of keeping the preinjury job was higher in large firms before the reforms (period 1) but the "size protection" effect disappeared after the reforms (period 3). Consistently the conditional probability of non-work was higher in smaller firms, but becomes not significantly different across firm sizes after the reforms, while the likelihood of finding a new job with only a temporary contract increases across all firms sizes.

\footnotetext{
${ }^{18}$ Average firm size is very small in Italy, as about one-third of private sector workers are employed in firms with less than 15 employees.

19 The same holds for wage in the next sub section.

20 The number of employees is a noisy measure of the legal threshold because such thresholds are defined by law not simply as a head count but with a set of cumbersome rules. Therefore, we prefer to assess changes around sizes that are clearly above or below the thresholds of 15 and 60 employees.
} 

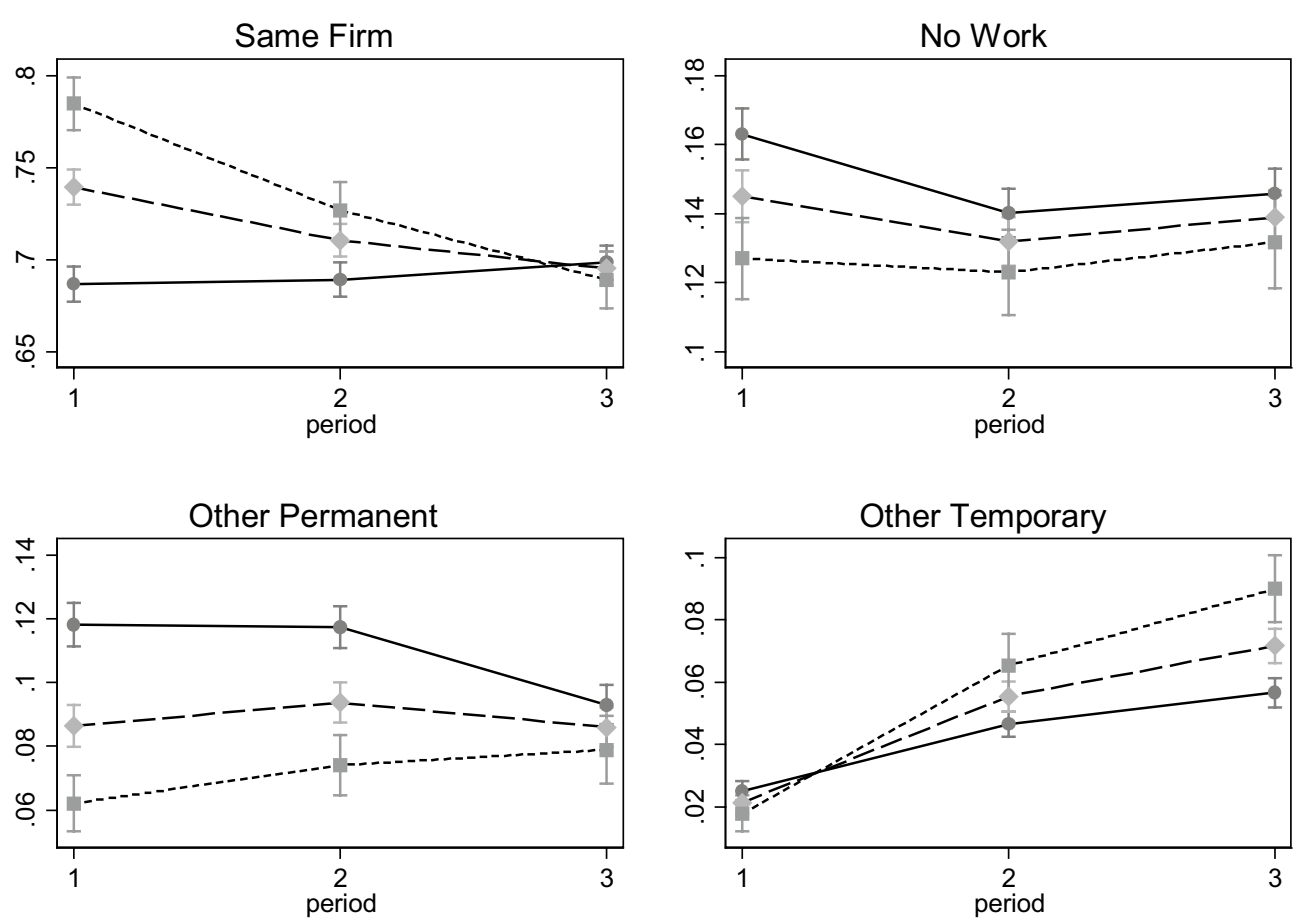

Fig. 1 Conditional probability of outcomes after 1 year since RTW by firm size (10, 100, 1000 employees). 90\% confidence intervals. Firm size 10 employees: solid lines; firm size 100 employees: dash lines; firm size 1000 employees: dotted lines

As discussed above, labor market deregulation focused on the creation of new more flexible temporary contacts, but ended up affecting the whole labor market functioning and shifted the bargaining power away from workers, regardless of their contractual status (Ciminelli et al. 2018). However, it is still possible that the results concerning the probability of remaining in the same firm hide differences in RTW success by pre-injury workers' contractual status. It is plausible that injured workers may benefit of more firm's good will and accommodations if originally hired with a permanent and not a temporary contract. To test this hypothesis, we also run our estimation after removing workers who had been working with a temporary contract at the time of the injury. We find that the conditional probability of remaining in the same firm for permanent contract workers only (about $90 \%$ of all workers in our sample) remains higher in correspondence of larger firm size, and does not change with the reforms. Hence, related to $\mathrm{Hp} 2$, we can conclude that being in a large firm does no longer guarantee job protection after the reforms only to those injured workers who were hired with a temporary contract at the time of the injury, despite that fact that the possibility of post injury accommodation should increase with size (Fig. 2: "Conditional probability of outcomes after one year since $R T W$, permanent contract workers only, by firm size (10, 100,
1000 employees)"). Results still hold after 3 years (Additional file 1: Figure S5).

We focus now on wages as a measure of human capital accumulation that could protect workers, as for Hp3. Figure 3 ("Conditional probability of outcomes after one year since $R T W$, by (real daily) wage quartiles $(50,60,70$ euro)") is analogous to the previous ones and shows conditional probabilities in correspondence of the first, second and third quartile of the real wage distribution (50, 60 and 70 euro per day). It shows that, as the reforms were introduced, workers with lower pre-injury wages became clearly less protected against labor market liberalization: they faced decreasing probability of remaining in their pre-injury firm, ended up with relative higher probability of no-work, and faced a higher likelihood of moving to a new firm under an only temporary contract (although differences are not strongly significant). Results after 3 years are similar, and statistical significance related to the probability of keeping the pre-injury job increases; the association of the reforms with the probability of nowork becomes milder (Additional file 1: Figure S6).

This time the results do not change when we limit our analysis to employees who were under permanent contracts when injured (Fig. 4: "Conditional probability of outcomes after one year since $R T W$, permanent contract workers only, by (real daily) wage quartiles $(50,60$, 70 euro)"). The conditional probabilities of keeping the 


\section{Same Firm}

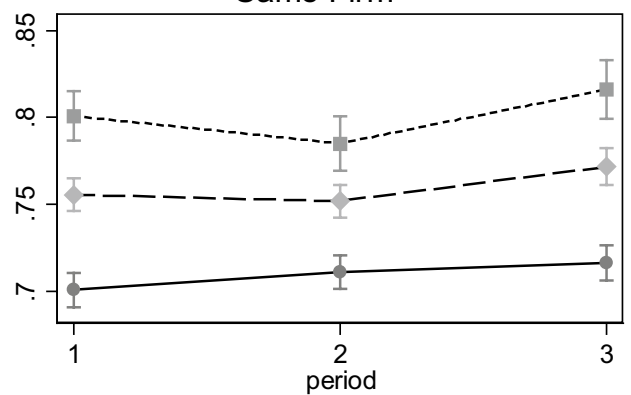

Other Permanent

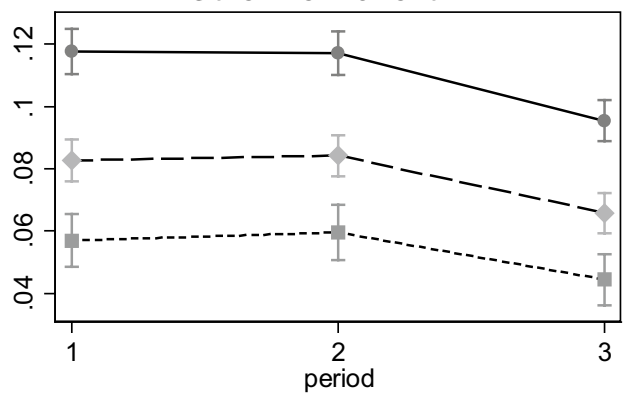

No Work

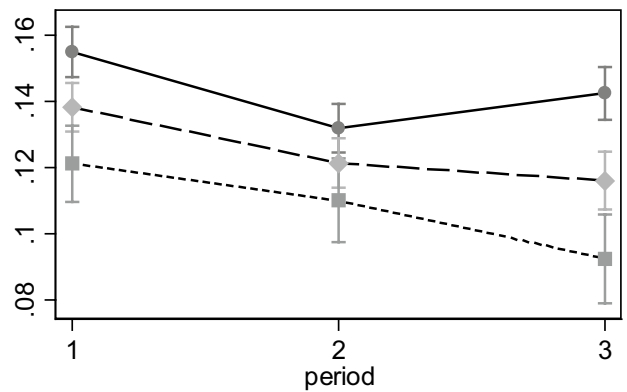

Other Temporary

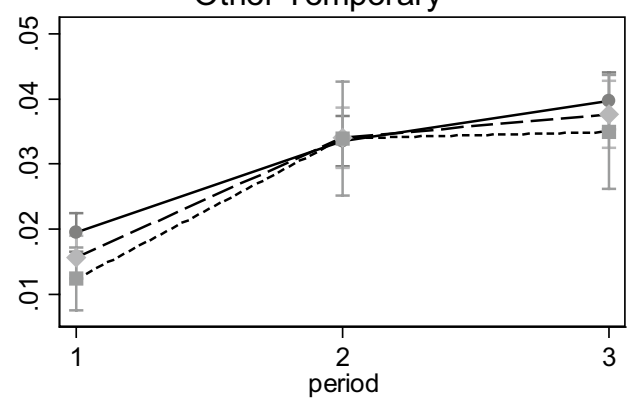

Fig. 2 Conditional probability of outcomes after 1 year since RTW, permanent contract workers only, by firm size (10, 100, 1000 employees). 90\% confidence intervals. Firm size 10 employees: solid lines; firm size 100 employees: dash lines; firm size 1000 employees: dotted lines
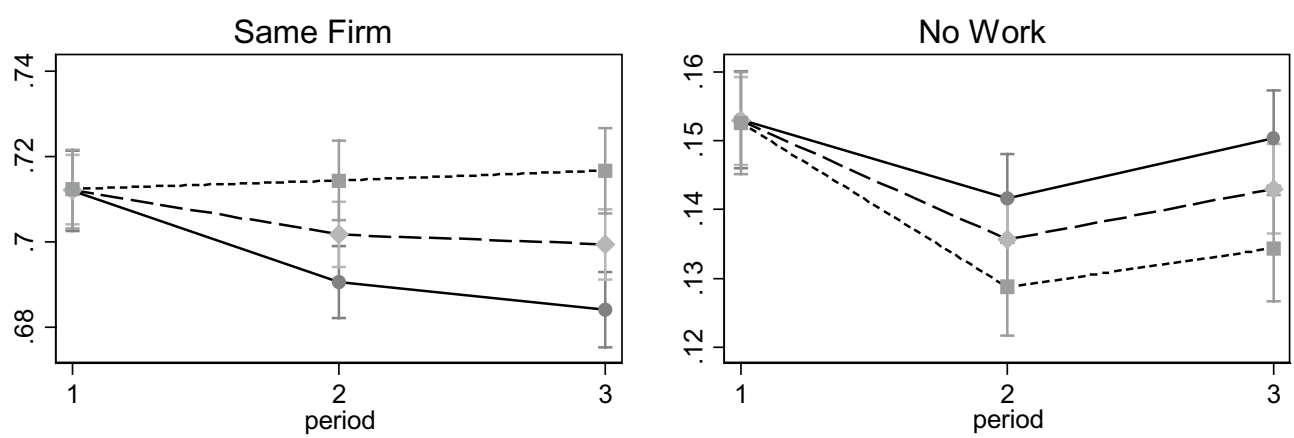

Other Permanent
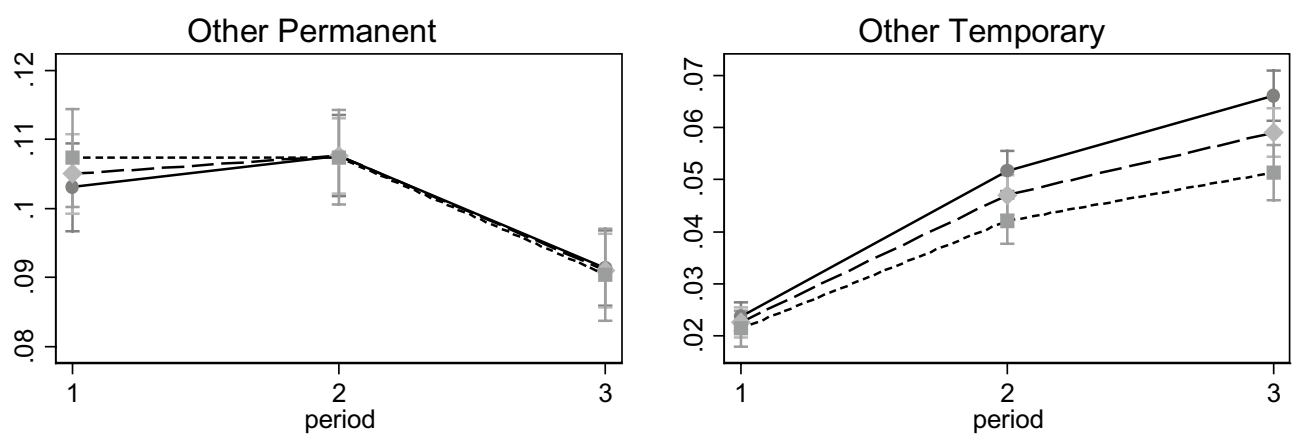

Fig. 3 Conditional probability of outcomes after 1 year since RTW, by (real daily) wage quartiles (50, 60, 70 euro). 90\% confidence intervals. Wage 50 euro: solid lines; Wage 60 euro: dash lines; Wage 70 euro: dotted lines 

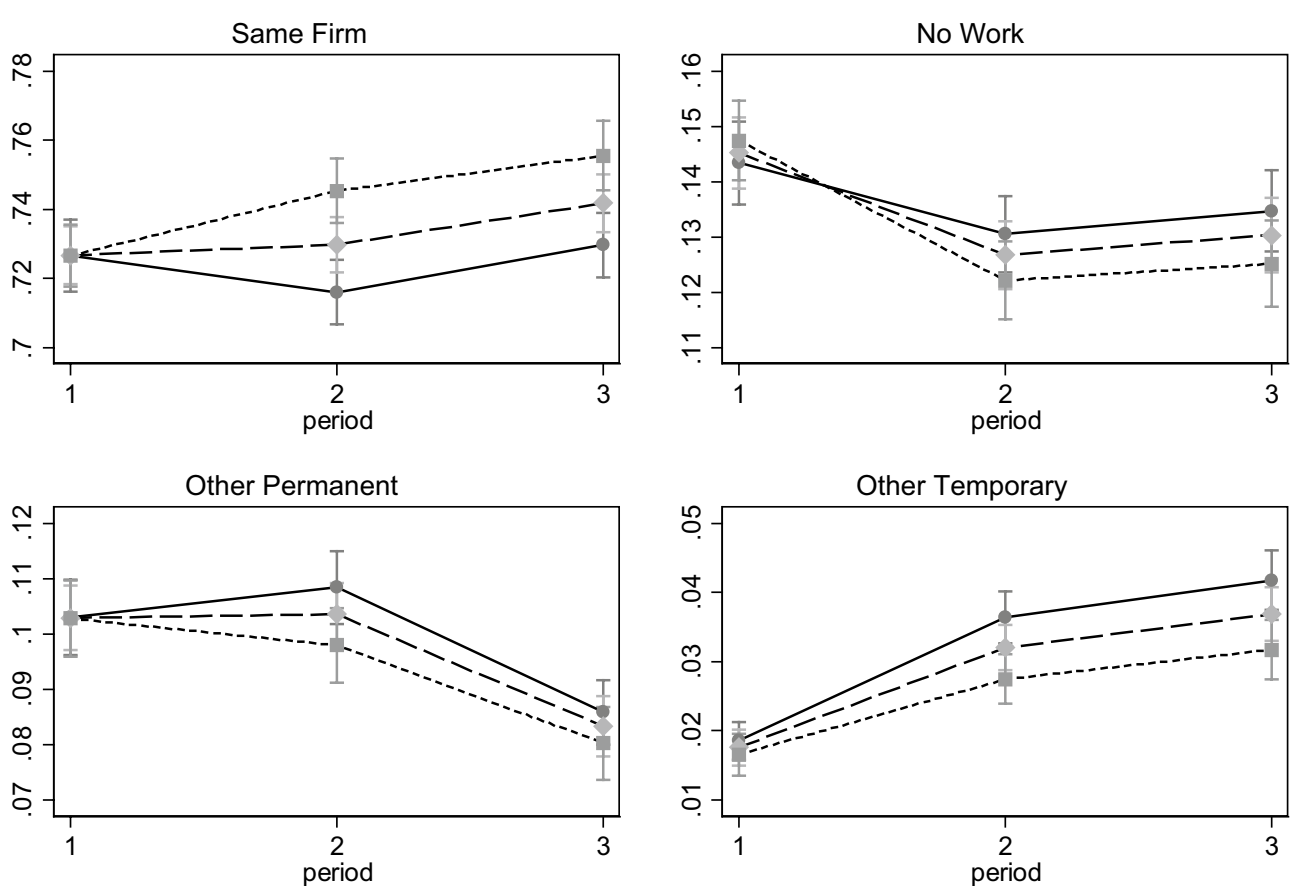

Fig. 4 Conditional probability of outcomes after 1 year since RTW, permanent contract workers only, by (real daily) wage quartiles (50, 60, 70 euro). $90 \%$ confidence intervals. Wage 50 euro: solid lines; Wage 60 euro: dash lines; Wage 70 euro: dotted lines

pre-injury job were not different by wage quartile before the reforms, but afterward they are different (although differences are not strongly significant). This holds after 3 years as well (Additional file 1: Figure S7) and is consistent with our $\mathrm{Hp} 3$.

Therefore, our first conclusion is that reforms ${ }^{21}$ were associated with changes in successful long term employment outcomes. Such outcomes became less linked with national employment protection rules, potential union protection, and firm's accommodation (linked to firm size), to become more a function of individual's human capital (as measured by wage). Such results confirm our first two hypotheses. Notice that-as discussed aboveour estimates (see as an example Table 4) control for (1) the individual propensity to move (number of pre-injury

\footnotetext{
$\overline{{ }^{21}}$ It is important to notice that, as discussed above a 2000 reform changed the compensation rules for PPD cases. The increased generosity of the system after 2000 may have increased the reservation wage and modified the labour supply of PPD workers, possibly reducing their labour force participation after the injury. As for the demand side, both before and after the 2000 reform employers remain entitled to legitimately lay off PPD workers only if they can prove that no accommodation can be provided within the firm. In general firms do not bear the immediate monetary costs of their PPD employees' compensation, so we do not expect a distortionary effect of 2000 law on our results. However, to check our results against the 2000 change in the compensation system, we performed a robustness check of our main findings excluding PPD workers from the analysis (Additional file 1: Figures S2, S3). Results did not change. We thank an anonymous referee for suggesting this check.
}

employment spells, interacted with periods), (2) total individual labor market experience (pre-injury days of employment, interacted with periods), and (3) firm's propensity not to invest in long-term relationships with the workforce (excess firm turnover interacted with periods). All these regressors have the expected sign-(1) and (3) decrease the probability to stay, (2) increases it-although the estimated values tend to increase during and after the reform periods.

\subsection{Severity of the injury}

When we focus on the role played by the severity of injury (captured bythe length of the spell off work), we find that more severe injuries were associated with lower conditional probability of keeping the pre injury job and higher conditional probability of non-work after 1 year (Fig. 5: "Conditional probability of outcomes after one year since $R T W$, by quartiles of number of days off after injury (9, 40,80 days)"). Surprisingly, none of the patters we study are correlated with the reform as lines remain pretty much parallel. The same outcome arises after 3 years (not reported). It is important to recall that our analysis controls also for other measures of general health (age, the annual frequency of pre-injury sick leaves, nature of the injury, and degree of potential PPD caused by the injury). All these regressors were also interacted with periods and we did not find significant interactions. 

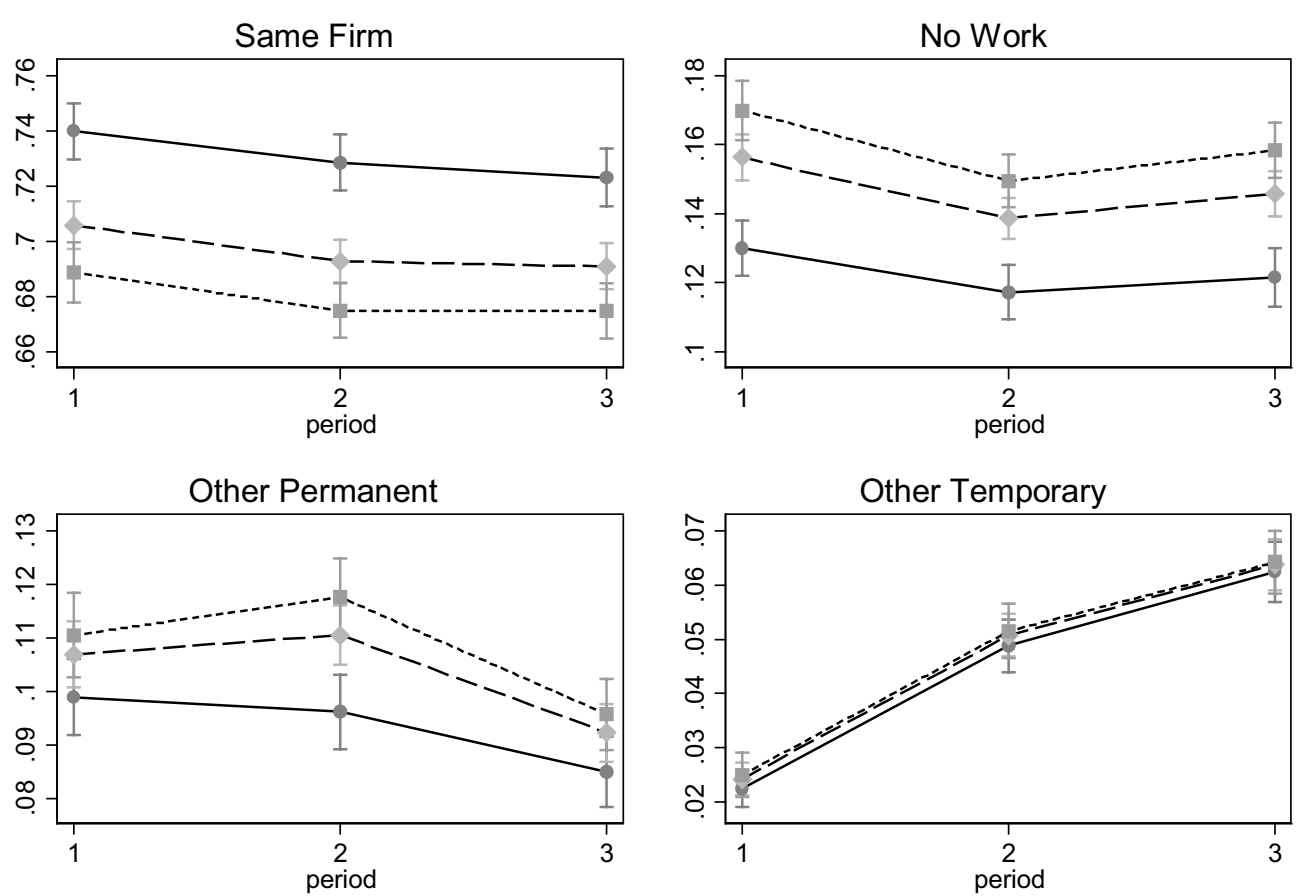

Fig. 5 Conditional probability of outcomes after 1 year since RTW, by quartiles of number of days of off after injury ( $9,40,80$ days). $90 \%$ confidence intervals. Days off work 9: solid lines; Days off work 40: dash lines; Days off work 80: dotted lines

Hence, our findings describe that the likelihood of different long-term employment outcomes by workers' injury severity was not associated with the reforms. Workers who were more vulnerable because of their worst injury experience did not experience a change in their probability of successful RTW over the reforms period we study. This contradicts our Hp. 4. However, it is important to notice that one more time, we observe a striking increase in the overall likelihood of landing on a new temporary job over the reforms period.

\subsection{Women and migrants}

To test our fourth hypothesis, we analyze our main results separately in the case of women and immigrants only. It is important to recall that the share of immigrants in our sample increased from 10 to $17 \%$ and to $26 \%$ over the three periods while the share of women remained stable around 9\%. Among women, temporary contracts increased more than in the whole sample, ${ }^{22}$ from $8 \%$, to $19 \%$, to $20 \%$ in the three periods considered; the same holds for immigrants, among which they increased from $8 \%$ to $16 \%$ to $19 \%$. Notice however that the smaller

\footnotetext{
${ }^{22}$ As shown in Table 2, in the whole sample the share of temporary contracts increased from $9 \%$ to $14 \%$ to $16 \%$.
}

sample size decreases the precision of the estimates with respect to the whole sample.

We focus on the conditional probability of keeping the pre-injury job after 1 year, for the sake of clarity and brevity. In Fig. 6 ("Conditional probability of staying in the same firm at one year, by firm size $(10,100,1000$ employees) and by (real daily) wage quartiles (50, 60, 70 euro)") we see that for both women and immigrants (regardless of contract type) the probability of remaining in the same firm flips after the reforms and becomes negatively related to firm size, showing a worsening of their long term employment outcomes during the reforms period compared to the whole population of injured workers (compare with Fig. 1). For immigrants, this process started as soon as the reforms rolled in (period 2); for women, as the reforms were completed (period 3). Both women and immigrants show the same pattern of the full sample with respect to the protective effect of high wages.

If, again, we exclude those working with a temporary contract at the time of the injury (Fig. 7: "Conditional probability of staying in the same firm at one year, by firm size (10, 100, 1000 employees) and by (real daily) wage quartiles (50, 60, 70 euro). Permanent contract workers only"), we see that-as in the whole sample-the effect related to wages is unchanged. However, the protective effect of firm size for permanent contract workers tends 
Women, by firm size

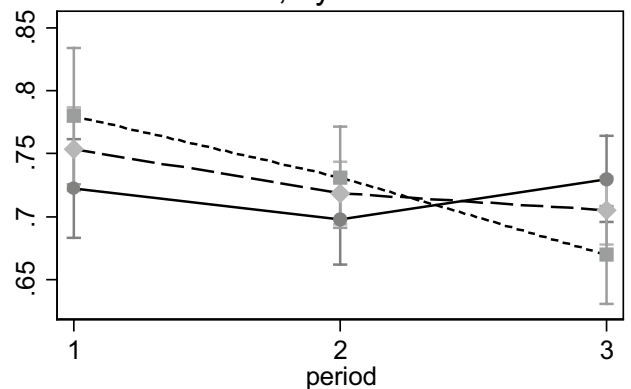

Women, by wage

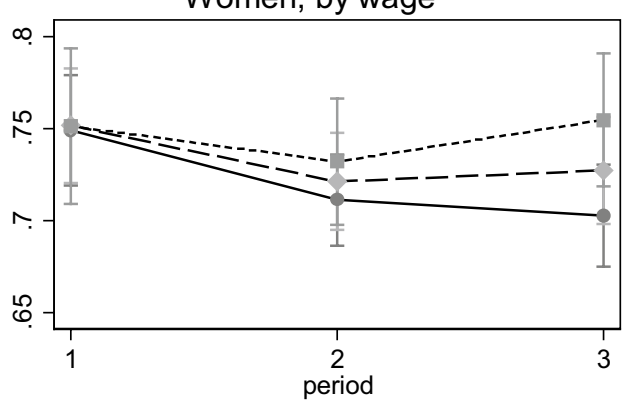

Not Native, by firm size

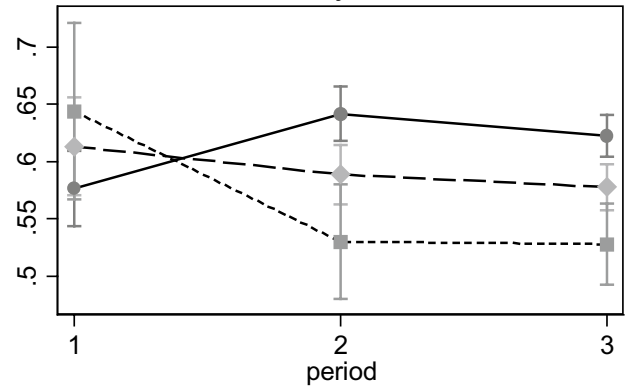

Not Native, by wage

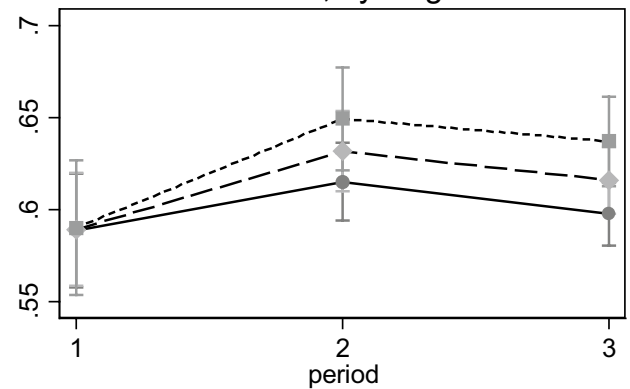

Fig. 6 Conditional probability of staying in the same firm at 1 year, by firm size (10, 100, 1000 employees) and by (real daily) wage quartiles (50, 60, 70 euro). 90\% confidence intervals. Firm size 10 employees: solid lines; firm size 100 employees: dash lines; firm size 1000 employees: dotted lines. Wage 50 euro: solid lines; Wage 60 euro: dash lines; Wage 70 euro: dotted lines

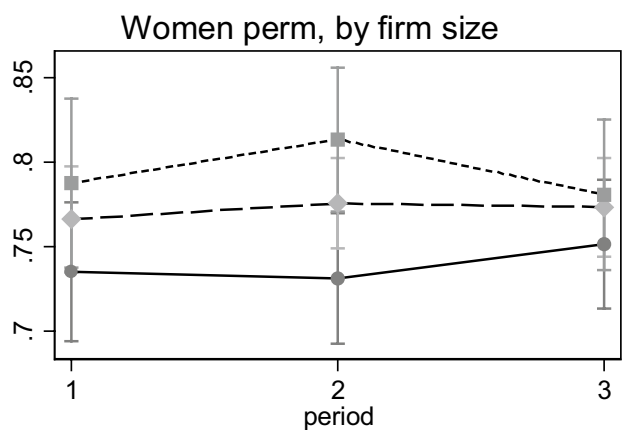

Women perm, by wage

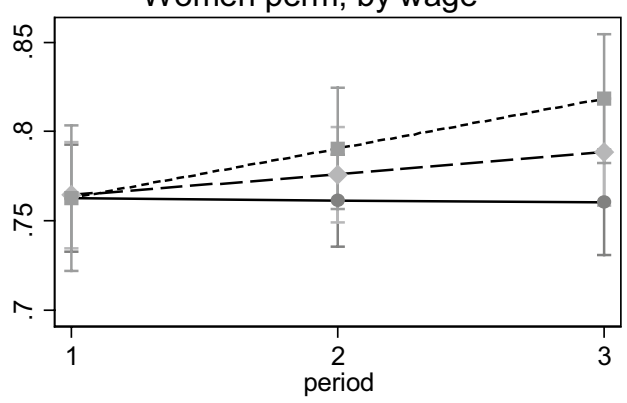

Not Native perm, by firm size

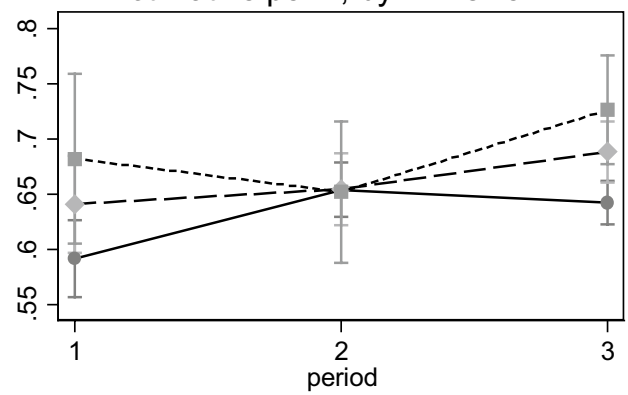

Not Native perm, by wage

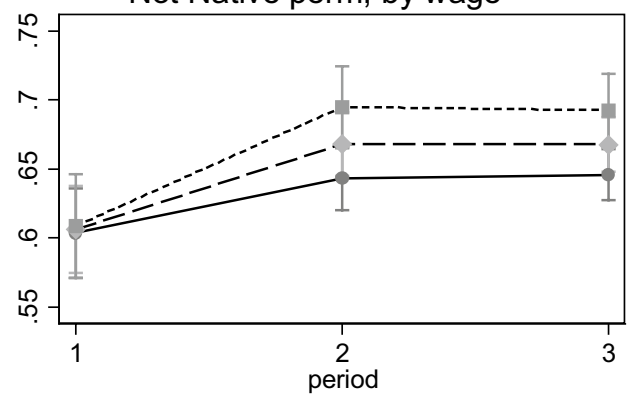

Fig. 7 Conditional probability of staying in the same firm at 1 year, by firm size (10, 100, 1000 employees) and by (real daily) wage quartiles (50, 60, 70 euro). Permanent contract workers only 90\% confidence intervals. Firm size 10 employees: solid lines; firm size 100 employees: dash lines; firm size 1000 employees: dotted lines. Wage 50 euro: solid lines; Wage 60 euro: dash lines; Wage 70 euro: dotted lines 
to fade away, during the reforms for migrants and after the reforms for women. This association may suggest that larger firms took advantage of the liberalization reforms to reduce the share of injured women and migrants on their payroll with a temporary contract and also of those they had previously hired with a permanent contract. This supports our Hp. 5, i.e. worsening employment outcomes for injured women and immigrants during and after the introduction of the reforms..

Finally, with respect to the severity of the incident and the consequent length of the absence, results related to women and immigrants are unchanged with respect to the whole sample (not reported): one more time reforms were found to be unrelated to the subsequent probability of non-work for injuries of different severities.

\subsection{Comparison of injured vs. non injured workers}

To better assess the implications of our findings, we should compare the observed employment outcomes for injured workers with the ones of Italian workers who did not experience an occupational incident. However, such direct comparison is not straightforward because we are focusing on a very specific subset of the population of workers (i.e. those more exposed to the risk of a work incident) and we study their employment experience after a quite relevant health shock (i.e. an injury that required immediate care). A counterfactual situation (i.e. workers exposed to a similar risk of a work injury but who did not experience it) cannot be easily found in the general working population, since a measure of occupational risk exposure is not reported in our data. Hence, the two comparison groups (injured $v s$ not injured) are composed of potentially very different individuals according to their observable and unobservable characteristics. Based on what we can observe in our WHIP data, ${ }^{23}$ the general working population (in not-agricultural private firms) is composed by more women, fewer migrants, fewer manual workers, and higher wage earners with respect to our sample of workers employed in more risky occupations (described in Table 2). The general working population is also exposed to the risk of a work incident for a shorter time: in fact, they have higher rates of part-time and less average work experience. All this would imply a quite different career path for our injured workers compared to non-injured employees regardless of the occurrence of a shock like a work incident.

Hence, following Fadlon and Nielsen (2017), we look for a more appropriate comparison. Our comparison group is drawn from the same sample of injured workers used in the main analysis, but is selected only among

${ }^{23}$ Results available under request. those who will face a work accident later in time. Here we are assuming that they all come from the same population of workers at risk, and that the time of the accident is random. In Fadlon and Nielsen's words (page 10) we "[...] compare households [workers in our case] with the same expectations over the distribution of future paths, but with different realizations, to isolate the unanticipated component of the shock [...] exploiting the potential randomness of the timing of a severe [...] health shock within a short period of time." Those authors proceed to estimate a proper impact evaluation applying a difference in differences strategy. However, the aim of our research is different, because we do not focus on the outcomes per se as they did, but on whether the consequences of the actual occurrence of an incident are associated with changes in the institutional setting of the labor market. In particular, we are interested on how the probability of the different outcomes is affected by covariates like firm size or individual wages and how the effect of such regressors varied over the reform period. Therefore, we replicate the analysis as in the previous figures (e.g. Fig. 1) and we compare the displayed patterns over the different reform periods. Finally, we use the estimated conditional probabilities to mimic a difference in differences comparison.

To be more specific, we proceed as follows. First, we attribute to not-yet-injured workers a random date of "pretend injury" and a random duration of "pretend leave", so that the distributions in the true and pretend injured samples are as similar as possible both in terms of time off work and tenure at the time of the incident (Additional file 1: Figures S10, S11). We impose that the "pretend date of injury" and "pretend day of "first" RTW" happen more than 1 year before the calendar day of the actual injury, so that we always measure their outcomes before the actual injury occurs. Unfortunately, in this case the sample size for period 3 (after the reforms) becomes quite small, because of the right censoring of work incident data at December 2005; estimates are less reliable for that period, hence we must focus mainly on periods before and during the reforms.

In terms of unconditional probabilities we calculate that our "not yet/pretend injured workers" face a much lower probability of no-work with respect to actual injured ones, and a higher probability of keeping their pre-injury job across the first two periods (Table 5). This seems to suggest a clear vulnerability of injured workers when the incident actually occurs.

Such general finding is confirmed when we replicate our multinomial logit analysis for the "not yet/pretend" injured group and plot again the conditional probabilities of the different outcomes in different periods (Fig. 8: "Not yet injured/pretend" injured workers: Conditional probabilities of staying in the same firm or not working 
Table 5 Comparison of unconditional probabilities of outcomes for "true" injured vs. "not yet/pretend" injured workers 1 year after "first" RTW

\begin{tabular}{|c|c|c|}
\hline & True & $\begin{array}{l}\text { Pretend-not } \\
\text { yet injured }\end{array}$ \\
\hline \multicolumn{3}{|l|}{ Injury in period 1-before 1994-1997 } \\
\hline Non work & 16.9 & 9.0 \\
\hline Employed in the same firm & 69.2 & 75.6 \\
\hline Employed in a different firm-permanent contract & 10.6 & 10.9 \\
\hline Employed in a different firm-temporary contract & 2.6 & 3.7 \\
\hline On leave due to a new_injury & 0.8 & 0.9 \\
\hline Total & 100.0 & 100.0 \\
\hline \multicolumn{3}{|l|}{ Injury in period 2-during 1998-2001 } \\
\hline Non work & 15.1 & 8.3 \\
\hline Employed in the same firm & 67.2 & 70.3 \\
\hline Employed in a different firm-permanent contract & 11.3 & 11.8 \\
\hline Employed in a different firm-temporary contract & 5.7 & 8.7 \\
\hline On leave due to a new_injury & 0.8 & 1.0 \\
\hline Total & 100.0 & 100.0 \\
\hline \multicolumn{3}{|l|}{ Injury in period 3-after 2002-2005 } \\
\hline Non work & 15.2 & 7.9 \\
\hline Employed in the same firm & 67.7 & 67.5 \\
\hline Employed in a different firm-permanent contract & 9.5 & 12.1 \\
\hline Employed in a different firm-temporary contract & 6.9 & 12.0 \\
\hline On leave due to a new_injury & 0.7 & 0.5 \\
\hline Total & 100.0 & 100.0 \\
\hline
\end{tabular}

one year after "pretend" RTW, by firm size (10, 100, 1000 employees)-first row-and by (real daily) wage quartiles (50, 60, 70 euro)-second row"; and Additional file 1: Figures S12, S13, S14, S15). We notice that over the reforms period (period 2) the "not yet/pretend" injured workers employed in small firms increase their probability to stay in the same firm one year after the imputed incident. ${ }^{24}$ This was not the case for the actual injured workers (back in Fig. 1). In addition the estimated probabilities of not working 1 year after the imputed incident day were much lower for workers in each firms size compared, again, to what was estimated for the real injured ones (Fig. 1). "Not yet/pretend" injured workers who earned low, median and high wages also increased their probability to stay in the same firm and decreased their probability of nowork during the reforms. Instead, the probability to stay in the same firm was decreasing among actually injured low wage workers, and it stayed constant for median and high wage ones; among actually injured workers the

\footnotetext{
${ }^{24}$ Results on only permanent contract workers disappear by firm size and are unchanged by wage, as in the sample of actual injured workers (see Additional file 1).
}

probability of no-work decreased, but to a lesser extent among low wage workers (see Fig. 3).

Finally, we use the point estimates and confidence intervals of the conditional probabilities of staying in the same firm, as in Figs. 1, 3, 8, and mimic a difference in differences comparison, without any possibility to verify the common trend assumption. However, we believe such assumption should hold because before period 1 both groups are "not yet injured". In Table 6 we note that actually injured workers suffer larger penalties in terms of the likelihood of remaining in the same firm 1 year after a "first" RTW, especially if they were employed in small firms and earned lower pre injury wages. This suggests that reforms were associated with a worsening of the conditions of the actually injured workers compared to the not injured ones because their longer term employment prospects became more uncertain.

\section{Discussion and conclusions}

The Italian labor market underwent a sequence of dramatic reforms between 1998 and 2001. Their goal was to increase labor market flexibility and, as a consequence, produce greater employment. New rules facilitated the creation of both more numerous and new types of flexible contracts. However, they ended up affecting the functioning of the whole labor market by eroding the bargaining power of all workers, including the ones hired with permanent contracts (Ciminelli et al. 2018). Our study describes the long term employment experience of injured workers during years when such reforms were introduced. Our data indicate that continuous work with the pre-injury employer remained the most common employment outcome for injured workers 1 year or 3 years after a "first" RTW. However, this was true for only around 70\% (after 1 year) and 50\% (after 3 years) of injured workers and such percentages remained overall stable before, during, and after reform periods. The second most common outcome, non-work, became a bit less frequent. Before the reform 25\% of injured workers were no longer employed 3 years after their "first" RTW. After the reform this percentage decreased to $23 \%$. More workers kept working but with a different employer and a temporary contract (from $6 \%$ before the reform to $11 \%$ after the reforms).

We estimate a multinomial logit model that accounts for individual, firm and injury characteristics as determinant of the different employment outcomes we observe. Our results are consistent with what shown by North American studies (Butler et al. 1995) despite the fact that we are studying a system with stronger institutional protections for injured workers. We find that injury severity was a main determinant of long term employment outcomes. At the same time, our measures of human capital 

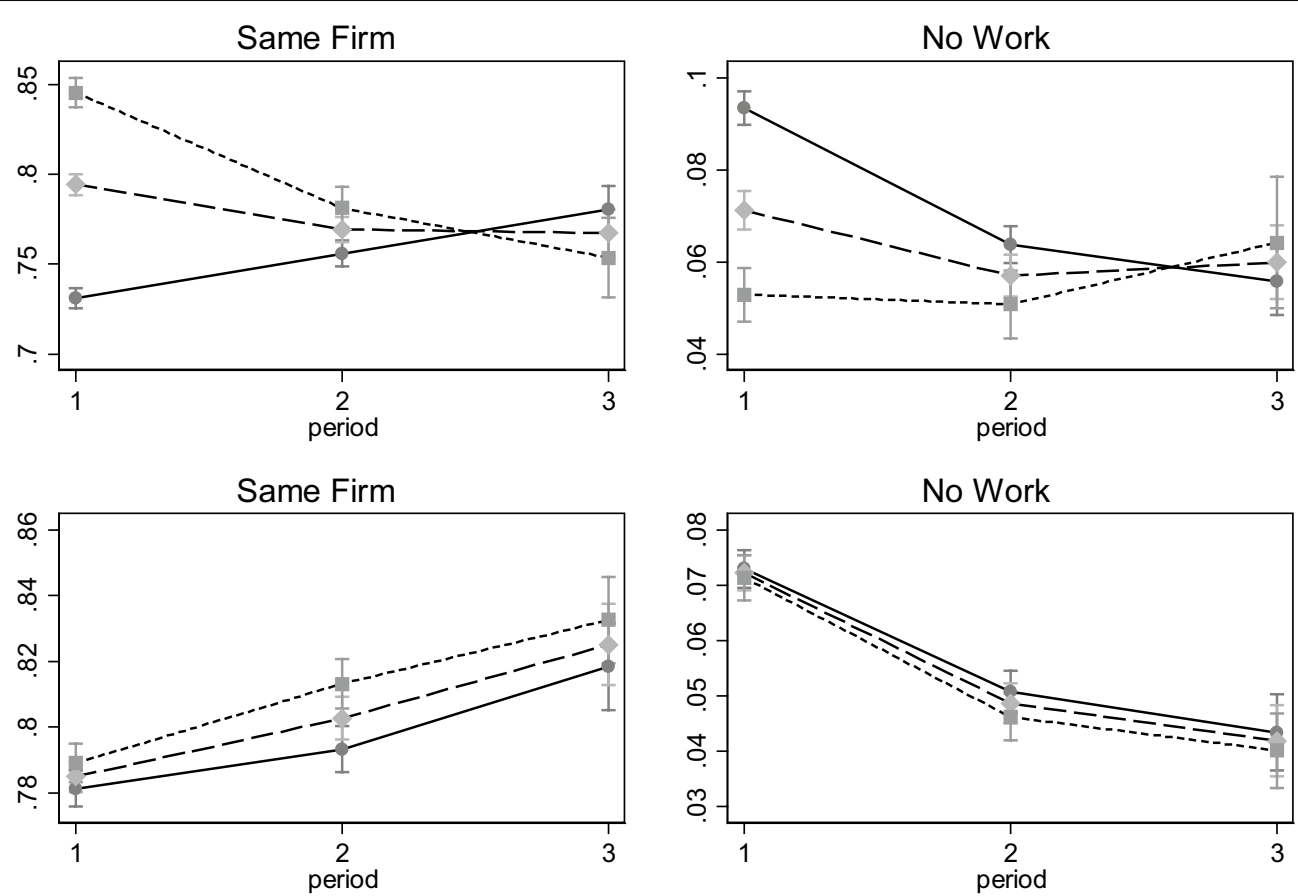

Fig. 8 "Not yet injured/pretend" injured workers: conditional probabilities of staying in the same firm or not working 1 year after "pretend" RTW, by firm size (10, 100, 1000 employees)—first row —and by (real daily) wage quartiles (50, 60, 70 euro)—second row—. 90\% confidence intervals. First row—firm size 10 employees: solid lines; Firm size 100 employees: dotted lines; Firm size 1000 employees: dotted lines. Second row—Wage 50 euro: solid lines; Wage 60 euro: dash lines; Wage 70 euro: dotted lines

accumulation (wages, relative wage status, labor market experience, employment stability) and of potential firms stability and ability to provide accommodations (stable employment, and size) were strong predictors of the most successful long term employment outcomes, i.e. ability to maintain employment with the preinjury employer. In addition, our estimations suggest that labor market liberalization reforms were associated with higher likelihood of maintaining employment after the injury and the "first" RTW. However, this happened at the expense of future job security: injured workers found more easily jobs with new employers, but fewer jobs with permanent contracts.

From previous studies we know that reforms weakened the employment protection that Italian workers had historically enjoyed when hired by larger firms, who face higher firing costs, stronger union representation, and likely offer more accommodations to the injured. We investigate whether specific firm and individual attributes offered "protection" from the potential destabilizing effects of the reforms. Contrary to the common expectation about women's weaker attachment to the labor force, we find that injured women were not more likely than men to stop working after a "first" RTW (as was already observed in Butler et al. 1995). We observe also that after the reforms, workers who were injured in larger establishments did not enjoy any longer a higher probability of long-term successful RTW (conditional on wages and the other controls), both in terms of their ability to keep their job with the pre-injury firms and in terms of losing employment (no work). Such loss of overall employment protection associated with firms' size was driven by the most vulnerable workers: the ones who at the time of the injury were already hired with flexible contracts (males or females), or the ones who were immigrants, even if hired with a permanent contract. This suggests that the traditionally more vulnerable workers were also the ones for whom the disadvantage in post-injury long term employment outcomes were amplified during the reforms. Liberalization gave employers more leeway in terms of decreasing any long-term commitment toward these employees with further implications for social inequality (Gebel and Giesecke 2009; Barbieri and Cutuli 2016.)

At the same time, our results confirm the importance of higher pre-injury wages (conditional on firm size and the other controls), in securing successful long-term employment. Previous research had already shown that higher wage workers are the more likely to return to work sooner after an incident (Galizzi et al. 2016). Given the same labor market experience, higher wage may proxy more successful investment in human capital 
Table 6 Difference in differences measure of conditional probabilities of outcomes (remaining with same employer) 1 year after "first" RTW

\begin{tabular}{|c|c|c|c|c|c|c|c|c|c|c|c|}
\hline \multirow{2}{*}{$\begin{array}{l}\text { Size } \\
\text { Small }\end{array}$} & \multirow{2}{*}{$\begin{array}{l}\text { Period } \\
2\end{array}$} & \multirow{2}{*}{$\begin{array}{l}\mathbf{T} / \mathbf{C} \\
T\end{array}$} & \multirow{2}{*}{$\begin{array}{r}\text { Margin } \\
0.689\end{array}$} & \multicolumn{2}{|c|}{$90 \%$ confidence interval } & \multirow{2}{*}{$\begin{array}{l}\text { Wage } \\
\text { Low }\end{array}$} & \multirow{2}{*}{$\begin{array}{l}\text { Period } \\
2\end{array}$} & \multirow{2}{*}{$\frac{T / C}{T}$} & \multirow{2}{*}{$\begin{array}{c}\text { Margin } \\
0.690\end{array}$} & \multicolumn{2}{|c|}{$90 \%$ confidence interval } \\
\hline & & & & 0.680 & 0.698 & & & & & 0.682 & 0.699 \\
\hline Small & 1 & $\mathrm{~T}$ & 0.687 & 0.677 & 0.696 & Low & 1 & $\mathrm{~T}$ & 0.712 & 0.702 & 0.721 \\
\hline Small & 2 & C & 0.756 & 0.749 & 0.763 & Low & 2 & C & 0.762 & 0.755 & 0.768 \\
\hline \multirow[t]{2}{*}{ Small } & 1 & C & 0.731 & 0.726 & 0.737 & Low & 1 & $C$ & 0.759 & 0.755 & 0.764 \\
\hline & & DID & -0.022 & -0.020 & -0.024 & & & $D I D$ & -0.024 & -0.021 & -0.026 \\
\hline Medium & 2 & T & 0.710 & 0.702 & 0.719 & Median & 2 & $T$ & 0.702 & 0.694 & 0.709 \\
\hline Medium & 1 & $\mathrm{~T}$ & 0.740 & 0.730 & 0.749 & Median & 1 & $\mathrm{~T}$ & 0.712 & 0.704 & 0.720 \\
\hline Medium & 2 & C & 0.769 & 0.762 & 0.776 & Median & 2 & $C$ & 0.768 & 0.761 & 0.774 \\
\hline \multirow[t]{2}{*}{ Medium } & 1 & $C$ & 0.794 & 0.789 & 0.800 & Median & 1 & $C$ & 0.760 & 0.755 & 0.765 \\
\hline & & DID & -0.004 & -0.002 & -0.006 & & & DID & -0.018 & -0.016 & -0.020 \\
\hline Large & 2 & $T$ & 0.727 & 0.712 & 0.742 & High & 2 & $\mathrm{~T}$ & 0.714 & 0.705 & 0.724 \\
\hline Large & 1 & $\mathrm{~T}$ & 0.785 & 0.770 & 0.799 & High & 1 & $\mathrm{~T}$ & 0.712 & 0.703 & 0.722 \\
\hline Large & 2 & C & 0.781 & 0.769 & 0.793 & High & 2 & C & 0.774 & 0.767 & 0.782 \\
\hline \multirow[t]{2}{*}{ Large } & 1 & $C$ & 0.845 & 0.837 & 0.854 & High & 1 & C & 0.761 & 0.754 & 0.767 \\
\hline & & $D I D$ & 0.006 & 0.009 & 0.004 & & & $D I D$ & -0.012 & -0.010 & -0.013 \\
\hline
\end{tabular}

and, therefore, a higher productivity that employers do not want to lose. Or it may signal higher worker's status within the company, another characteristic that may lead to higher likelihood of receiving accommodation by employers. The findings of our current study suggest that such factors are determinant also of successful employment outcomes over the long run despite the potential higher flexibility introduced by reforms. Our estimates show that only high wage workers kept being more likely to maintain their job with the pre-injury employer, or to avoid non work or a temporary contract if they changed employer one or 3 years after their "first" RTW, even if they were women or immigrants.

Finally, we find that workers with a higher degree of permanent disability were clearly more likely to stop working overtime. Workers who took long time to recover from the injury were also more likely to separate from the preinjury employer. However, we do not observe any changes in such trends over the three periods we observe. Clearly, the worst the injury, the bigger the challenges across all the employment outcomes we studied. However, liberalization of the labor market was associated with neither worsened nor improved employment outcomes $1 / 3$ years after the day of maximum medical improvement across the different levels of injury severity.

We acknowledge that our study has limitations. Because the reforms were introduced gradually and at times of additional institutional changes, we cannot implement a clear before-after policy evaluations design to provide clear evidence of a causal impact of the liberalization. Furthermore, our data is quite rich in terms of recorded workers', firms', and injuries' characteristics, but it does not permit us to compare the experience of injured workers with the ones of similar workers employed, for example, in the same occupation and in the same firms. This limits our ability to establish clearly whether the reforms were associated with different outcomes for injured and non-injured employees. However, the comparison exercise we conducted using "not yet injured workers" as a comparison group suggests that during and after the reforms employment uncertainty may have increased more for injured workers than for the non-injured ones. This is clearly an area that should be further tested with different data sets.

Our study represents also only a first step in our effort to describe how injured workers well-being may change over a period when labor market reforms are introduced. We assess our outcomes mainly in terms of job/employment security, but other dimensions of job quality such as wages, job title, and full vs. part time status are also very important dimensions of employment quality, and they deserve further analysis. Although our measures of long term employment outcomes enrich the ones used in previous studies by considering also the degree of job security attached to new employment contracts, we are aware that it remains an imperfect measure of potential success. Individuals differ in their needs, desires and aspirations. Therefore, a RTW on a job that is less secure but pays better or promises immediate or future promotions may be a preferable outcome to certain injured workers (Young 2014). Similarly, to certain individuals a temporary job that comes with more interesting duties, or with flexible time, could be more desirable than a more structured, permanent but less flexible job (Krause 
et al. 2001; Berecki-Gisolf et al. 2012; Young et al. 2005b; Leyshon and Shaw 2012). Finally, a RTW to a secure job may still be not successful if the worker keeps experiencing physical or mental health limitations (Bültmann et al. 2007). These are job dimensions and workers' preferences that cannot be captured by our administrative data and will require survey or qualitative data.

Despite such limitations, our study provides new evidence that policies aiming at improving RTW need to focus also on interventions that will affect a "successful" RTW, i.e. long term employment. Almost one-fourth of our Italian injured workers were no longer working 3 years after a "first" RTW. This calls for incentives to induce firms to accommodate not only their most valuable (high wage, high status, long experience) employees but also the most "disposable" ones. In addition, we provide original evidence that the outcomes of occupational injuries do not happen in a vacuum, and are not only affected by workers' compensation, disability, or human resource policies. They are correlated also with the more general rules that affect each country labor market. This implies that policies regulating the experience of injured workers need to be aware that their final effect is likely to depend on a much wider set of national or sectoral labor market regulations that will strengthen or weaken the "protective" effect of specific firms or individual attributes. At the same time, general labor market policies reforms cannot forget how they will end up framing the experiences of some of the less visible, but more vulnerable workers, such as the ones who carried already the burden of an occupational injury.

Our findings show that labor market liberalization policies were associated with changes in outcomes for all injured workers, regardless of their pre-injury contractual status. During and after the reforms were introduced such workers found easier to find new-but less secure- employment. This has very important implications. Temporary contracts have been found to have a negative effect on productivity (Lisi and Malo 2017). Furthermore, there is evidence that more insecure jobs are associated with higher frequency and severity of injuries (Amuedo-Dorantes 2002; Guadalupe 2003; Fabiano et al. 2008; Bender et al. 2012; Picchio and Van Ours 2017) and, more generally, higher risk of poor health, of future sickness absences, and of larger use of health services (László et al. 2010). All these negative consequences are likely to be amplified for a person who already suffered an injury and ends up being reemployed in a more insecure job. Therefore, workers' compensation policies and labor market liberalization policies need to be highly coordinated to avoid severe unintended consequences as higher costs caused by new lost production and medical expenses.

\section{Additional file}

Additional file 1 This file includes robustness checks for our multinomial estimations; display of the conditional probabilities of outcomes 3 years after the "first" RTW; display of the probabilities of "no work" for women and immigrants 1 year after the "first" RTW; and additional comparisons of selected characteristics and outcomes between truly injured and "pretend/not yet injured" workers.

\section{Acknowledgements}

Not applicable.

\section{Authors' contributions}

MG participated in the (i) conception and design of the work; (ii) interpretation of statistical results data for the work; (iii) drafting the work and revising it critically for important intellectual content; (iv) final approval of the version to be published; and ( $v$ ) agreement to be accountable for all aspects of the work in ensuring that questions related to the accuracy or integrity of any part of the work are appropriately investigated and resolved. RL participated in the (i) acquisition, preparation, and interpretation of data for the work; (ii) drafting the work and revising it critically for important intellectual content; (iii) final approval of the version to be published; and (iv) agreement to be accountable for all aspects of the work in ensuring that questions related to the accuracy or integrity of any part of the work are appropriately investigated and resolved. LP participated in the (i) design of the work; (ii) econometric analysis, and interpretation of empirical results for the work; (ii) drafting the work and revising it critically for important intellectual content; (iii) final approval of the version to be published; and (iv) agreement to be accountable for all aspects of the work in ensuring that questions related to the accuracy or integrity of any part of the work are appropriately investigated and resolved. All authors read and approved the final manuscript.

\section{Funding}

This research was not supported by external funding.

\section{Availability of data and materials}

The data that support the findings of this study are available from Italian Ministry of Health but restrictions apply to the availability of these data, which were used under license for the current study, and so are not publicly available. As explained in footnote 8 the authors are available to guide through the procedures for accessing and to make available the computer programs used to generate the results.

\section{Competing interests}

The authors declare that they have no competing interests.

\section{Author details}

1 Department of Economics, University of Massachusetts Lowell, Lowell, MA 01854-2881, USA. ${ }^{2}$ Department of Economics and Statistics, University of Torino, 10153 Turin, Italy. ${ }^{3}$ Laboratorio R. Revelli, Turin, Italy.

Received: 27 July 2018 Accepted: 29 May 2019

Published online: 12 June 2019

\footnotetext{
References

Amuedo-Dorantes, C.: Work safety in the context of temporary employment: the Spanish experience. ILR Rev. 55(2), 262-285 (2002)

Anema, J.R., Schellart, A.J.M., Cassidy, J.D., Loisel, P., Veerman, T.J., van der Beek, A.J.: Can cross country differences in return-to-work after chronic occupational back pain be explained? An exploratory analysis on disability policies in a six country cohort study. J. Occup. Rehabil. 19(4), 419-426 (2009)

Awang, H., Shahabudin, S.M., Mansor, N.: Return-to-work program for injured workers: factors of successful return to employment. Asia Pac. J. Public Health 28(8), 694-702 (2016)

Barbieri, P., Cutuli, G.: Employment protection, labour market dualism, and inequality in Europe. Eur. Sociol. Rev. 32, 501-516 (2016)
} 
Barbieri, P., Scherer, S.: Labour market flexibilization and its consequences in Italy. Eur. Sociol. Rev. 25, 677-692 (2009)

Barr, B., Clayton, S., Whitehead, M., et al.: To what extent have relaxed eligibility requirements and increased generosity of disability benefits acted as disincentives for employment? A systematic review of evidence from countries with well-developed welfare systems. J. Epidemiol. Community Health 64(12), 1106-1114 (2010)

Bena, A., Leombruni, R., Giraudo, M., Costa, G.: A new Italian surveillance system for occupational injuries: characteristics and initial results.". Am. J. Ind. Med. 55(7), 584-592 (2012)

Bender, K.A., Green, C.P., Heywood, J.S.: Piece rates and workplace injury: Does survey evidence support Adam Smith? J. Popul. Econ. 25(2), 569-590 (2012)

Berecki-Gisolf, J., Clay, F.J., Collie, A., McClure, R.J.: Predictors of sustained return to work after work-related injury or disease: insights from workers' compensation claims records. J. Occup. Rehabil. 22(3), 283-291 (2012)

Bertola, G.: Job security, employment and wages. Eur. Econ. Rev. 34(4), 851-879 (1990)

Berton, F., Devicienti, F., Pacelli, L:: Are temporary jobs a port of entry into permanent employment?: Evidence from matched employer-employee. Int. J. Manpow. 32(8), 879-899 (2011)

Berton, F., Richiardi, M., Sacchi, S.: The political economy of work security and flexibility: Italy in comparative perspective. Policy Press; distributed by University of Chicago Press, Bristol (2012)

Biering, K., Hjøllund, N.H., Lund, T.: Methods in measuring return to work: a comparison of measures of return to work following treatment of coronary heart disease. J. Occup. Rehabil. 23(3), 400-405 (2013)

Boden, L.I., Galizzi, M.: Blinded by Moral Hazard. Rutgers Univ. Law Rev. 69(3), 1213-1232 (2017)

Boden, L.I., Ozonoff, A.: Capture-recapture estimates of nonfatal workplace injuries and illnesses. Ann. Epidemiol. 18(6), 500-506 (2008)

Bültmann, U., Franche, R.-L., Hogg-Johnson, S., et al.: Health status, work limitations, and return-to-work trajectories in injured workers with musculoskeletal disorders. Qual. Life Res. 16(7), 1167-1178 (2007)

Burkhauser, R.V., Daly, M.C., Ziebarth, N.R.: Protecting working-age people with disabilities: experiences of four industrialized nations. I Labour Mark. Res 49, 367-386 (2016)

Butler, R.J., Johnson, W.G., Baldwin, M.L.: Managing work disability: why first return to work is not a measure of success. Ind. Labor Relat. Rev. 48(3), 452-469 (1995)

Cavaletto, G., Pacelli, L.: Flessibilità del lavoro e formazione dei lavoratori. II caso italiano. Polis, Ricerche e studi su società e politica in Italia 2, 251-286 (2014)

Ciminelli, G., Duval, R., Furceti, D.: Employment Protection Deregulation and Labor Shares in Advanced Economies. International Monetary Fund. WP/18/186. https://www.imf.org/en/Publications/WP/Issues/2018/08/16/ Employment-Protection-Deregulation-and-Labor-Shares-in-AdvancedEconomies-46074. (2018). Accessed 8 Jan 2019

Clayton, S., Barr, B., Nylen, L., et al.: Effectiveness of return-to-work interventions for disabled people: a systematic review of government initiatives focused on changing the behaviour of employers. Eur. J. Pub. Health 22(3), 434-439 (2012)

Collie, A., Lane, T.J., Hassani-Mahmooei, B., Thompson, J., McLeod, C.: Does time off work after injury vary by jurisdiction? A comparative study of eight Australian workers' compensation systems. BMJ Open 6(5), e010910 (2016)

Côté, P., Baldwin, M.L., Johnson, W.G., Frank, J.W., Butler, R.J.: Patterns of sickleave and health outcomes in injured workers with back pain. Eur. Spine J. 17(4), 484-493 (2008)

Cullen, K.L., Irvin, E., Collie, A., et al.: Effectiveness of workplace interventions in return-to-work for musculoskeletal, pain-related and mental health conditions: an update of the evidence and messages for practitioners. J. Occup. Rehabil. 28, 1-15 (2018)

Eurostat. Database. European Commission. Available at: http://ec.europa.eu/ eurostat/data/database. (2018). Accessed May 72018

Fabiano, B., Currò, F., Reverberi, A.P., Pastorino, R.: A statistical study on temporary work and occupational accidents: specific risk factors and risk management strategies. Saf. Sci. 46(3), 535-544 (2008)

Fadlon, I., Nielsen, TH.: Family labor supply responses to severe health shocks. (2017). NBER working paper 21352
Gailey, A.H., Seabury, S.A.: The impact of employment protection on workers disabled by workplace injuries. In: Kessler, D.P. (ed.) Regulation versus litigation: perspectives from economics and law: a National Bureau of Economic Research Conference Report. University of Chicago Press, Chicago and London (2010)

Galizzi, M.: On the recurrence of occupational injuries and workers' compensation claims. Health Econ. 22(5), 582-599 (2013)

Galizzi, M., Leombruni, R., Pacelli, L., Bena, A.: Injured workers and their return to work. Beyond individual disability and economic incentives. Evid. Based HRM. 4(1), 2-29 (2016)

García-Serrano, C., Hernanz, V., Toharia, L.: Mind the gap, please! The effect of temporary help agencies on the consequences of work accidents. J. Labor Res. 31(2), 162-182 (2010)

Gebel, M., Giesecke, J.: Labour market flexibility and inequality: the changing risk patterns of temporary employment in West Germany. Zeitschrift für ArbeitsmarktForschung 42, 234-251 (2009)

Giannelli, G.C., Jaenichen, U., Villosio, C.: have labor market reforms at the turn of the millennium changed the job and employment durations of new entrants? J. Labor Res. 33, 143 (2012)

Giraudo, M., Bena, A., Leombruni, R., Costa, G.: Occupational injuries in times of labour market flexibility: the different stories of employment-secure and precarious workers. BMC Public Health. 16, 150 (2016)

Guadalupe, M.: The hidden costs of fixed term contracts: the impact on work accidents. Labour Econ. 10(3), 339-357 (2003)

Høgelund, J., Holm, A.: Worker adaptation and workplace accommodations after the onset of an illness. IZA J. Labor Policy 3, 17 (2014)

INAIL- Istituto Nazionale per I'Assicurazione contro gli Infortuni sul Lavoro." "I costo dei Danni da lavoro per l'Azienda Italia" http://www.inail.it/inter net_web/wcm/idc/groups/internet/documents/document/ucm_08627 6.pdf. (2011). Accessed 5 June 2015

Institute for Work \& Health:. Workers' compensation and the business cycle. March. https://www.iwh.on.ca/briefings/business-cycle. (2009)

Kahn, L.: Employment protection reforms, employment and the incidence of temporary jobs in Europe: 1996-2001. Labour Econ. 17(1), 1-15 (2010)

Koranyi, I., Jonsson, J., Rönnblad, T., Stockfelt, L., Bodin, T.: Precarious employment and occupational accidents and injuries - a systematic review. Scand. J. Work Environ. Health 44(4), 341-350 (2018)

Krause, N., Frank, J.W., Dasinger, L.K., Sullivan, T.J., Sinclair, S.J.: Determinants of duration of disability and return-to-work after work-related injury and illness: challenges for future research. Am. J. Ind. Med. 40(4), 464-484 (2001)

László, K.D., Pikhart, H., Kopp, M.S., et al.: Job insecurity and health: a study of 16 European countries. Soc. Sci. Med. 70(6), 867-874 (2010)

Leombruni, R., Paggiaro, A., Trivellato, U.: Per un pugno di euro. Storie di ordinaria disoccupazione. Politica Economica 28(1), 5-47 (2012)

Leyshon, R., Shaw, L.: Using multiple stakeholders to define a successful return to work: a concept mapping approach. Work 41(4), 397-408 (2012)

Lisi, D., Malo, M.A.: The impact of temporary employment on productivity. J. Labour Mark. Res 50, 91-112 (2017)

Oleinick, A., Gluck, J.V., Guire, K.E.: Establishment size and risk of occupational injury. Am. J. Ind. Med. 28(1), 1-21 (1995)

Olivetti, C., Petrongolo, B.: Unequal pay or unequal employment? A crosscountry analysis of gender gaps. J. Labor Econ. 26(4), 621-654 (2008)

Picchio, M., Van Ours, J.C.:Temporary jobs and the severity of workplace accidents. J. Saf. Res. 61, 41-51 (2017)

Rossi, P: The new system of compensation of occupational accidents and diseases: features and details of the reform introducing the concept of biological damage. La Medicina del lavoro 93(2), 108-117 (2002)

Seing, I., MacEachen, E., Ståhl, C., Ekberg, K.: Early-return-to-work in the context of an intensification of working life and changing employment relationships. J. Occup. Rehabil. 25(1), 74-85 (2015)

Strunin, L., Boden, L.I.: The workers' compensation system: worker friend or foe? Am. J. Ind. Med. 45(4), 338-345 (2004)

Venturini, A., Villosio, C.: Labour-Market Assimilation of Foreign Workers in Italy. Oxford Rev. Econ. Policy 24(3), 517-541 (2008)

Vogel, A.P., Barker, S.J., Young, A.E., Ruseckaite, R., Collie, A.: What is return to work? An investigation into the quantification of return to work. Int. Arch. Occup. Environ. Health 84(6), 675-682 (2011)

Wuellner, S.E., Adams, D.A., Bonauto, D.K.: Unreported workers' compensation claims to the BLS Survey of Occupational Injuries and IIInesses: establishment factors. Am. J. Ind. Med. 59(4), 274-289 (2016) 
Young, A.E., Roessler, R.T., Wasiak, R., McPherson, K.M., van Poppel, M.N.M. Anema, J.R.: A developmental conceptualization of return to work. J. Occup. Rehabil. 15(4), 557-568 (2005a)

Young, A.E., Wasiak, R., Roessler, R.T., McPherson, K.M., Anema, J.R., van Poppel, M.N.M.: Return-to-work outcomes following work disability: stakeholder motivations, interests and concerns. J. Occup. Rehabil. 15(4), 543-556 (2005b)
Young, A.E.: An exploration of alternative methods for assessing return-to-work success following occupational injury. Disabil. Rehabil. 36(11), 914-924 (2014)

\section{Publisher's Note}

Springer Nature remains neutral with regard to jurisdictional claims in published maps and institutional affiliations.

\section{Submit your manuscript to a SpringerOpen ${ }^{\mathcal{O}}$ journal and benefit from:}

- Convenient online submission

- Rigorous peer review

- Open access: articles freely available online

- High visibility within the field

- Retaining the copyright to your article

Submit your next manuscript at $\boldsymbol{\nabla}$ springeropen.com 